\title{
WILEY-VCH
}

DOI: 10.1002/ ((please add manuscript number))

Article type: Review

\section{Interfacing Materials Science and Biology for Drug Carrier Design}

Georgina K. Such, Yan Yan, Angus P. R. Johnston, Sylvia T. Gunawan, and Frank Caruso*

Dr. G. K. Such

School of Chemistry

The University of Melbourne

Parkville, Victoria 3010, Australia

Dr. Y. Yan, S. T. Gunawan, Prof. F. Caruso

ARC Centre of Excellence in Convergent Bio-Nano Science and Technology, and the Department of Chemical and Biomolecular Engineering

The University of Melbourne

Parkville, Victoria 3010, Australia

E-mail: fcaruso@unimelb.edu.au

Dr. A. P. R. Johnston

ARC Centre of Excellence in Convergent Bio-Nano Science and Technology, and Drug

Delivery, Disposition and Dynamics, Monash Institute of Pharmaceutical Sciences

Monash University

381 Royal Parade, Parkville, Victoria 3052, Australia

Keywords: polymer carriers, drug delivery, $\mathrm{pH}$, redox, enzyme.

Over the last ten years, there has been considerable research interest in the development of polymeric carriers for biomedicine. Such delivery systems have the potential to significantly reduce side effects and increase the bioavailability of poorly soluble therapeutics. The design of carriers has relied on harnessing specific variations in biological conditions, such as $\mathrm{pH}$ or redox potential, and more recently, by incorporating specific peptide cleavage sites for enzymatic hydrolysis. Although much progress has been made in this field, the specificity of polymeric carriers is still limited when compared with their biological counterparts. To synthesize the next generation of carriers, it is important to consider the biological rationale for materials design. This requires a detailed understanding of the cellular microenvironments and how these can be harnessed for specific applications. In this review, we outline several important physiological cues in the cellular microenvironments, focusing on changes in $\mathrm{pH}$, 


\section{WILEY-VCH}

redox potential, and the types of enzymes present in specific regions. Furthermore, we highlight recent studies that use such biologically inspired triggers to design polymeric carriers, focusing on applications in the field of therapeutic delivery.

\section{Introduction}

Recent advances in materials synthesis have provided a versatile platform to design polymer films and particles with engineered properties and functions. ${ }^{[1]}$ These materials have generated significant interest in the areas of energy, environment, and biomedicine. The development of polymeric carriers for therapeutic delivery is of particular interest for material scientists because engineered carriers have the potential to improve healthcare by reducing side effects and increasing the types of applicable drugs. ${ }^{[2]}$ Fundamental to the successful design of such carriers are their 'smart' capabilities to load and release therapeutics specifically at a target site. ${ }^{[3]}$ Although there has been significant progress towards achieving this goal, there are still lessons to be learnt from nature regarding the integration of 'smart' features into synthetic materials. ${ }^{[4,5]}$ Currently, there is considerable research on designing polymeric carriers that incorporate biologically responsive components such as linkages that cleave upon change in $\mathrm{pH}$ or redox potential. However, further exploitation of these mechanisms is required to assemble carriers with tailored and enhanced properties. Using customized peptides is another approach towards integrating biological responses, whereby biological catalysts (i.e., enzymes) are employed to induce specific reactions with the substrate. Although studies using this approach are limited, such a strategy offers significant potential for engineering carriers that can mimic 'smart' behaviors observed in proteins.

To develop the next generation of polymeric carriers, it is important to consider the biological environments for which the materials are designed. A thorough understanding of the cellular microenvironment is essential, for example, the specific biological conditions (e.g., 


\section{WILEY-VCH}

cytoplasm) that are required for particular applications and the different environmental barriers (e.g., endo/lysosomes) that polymeric carriers must navigate through. Obtaining a detailed understanding of useful biological triggers, relevant cellular conditions, and molecular concentration ranges can be challenging from a materials science perspective because of the complexity of the biology.

This review focuses on the design of polymeric carriers that respond to specific biological conditions. The first part of the review provides a set of biological guidelines for $\mathrm{pH}$, redox, and enzyme variations within different intra/extracellular regions. The second part highlights the progress made to date on engineering polymeric carriers that respond to such stimuli to induce carrier degradation and/or loading and release for drug or gene delivery applications. This review specifically focuses on recent studies - details of previous studies on polymeric carriers can be obtained in other reviews. ${ }^{[1,6]}$

\section{Biological Environment}

Therapeutics target specific biological processes that occur in different cellular regions. Thus, to achieve optimal therapeutic effects, the delivery of drugs to the desired site of action is required. For example, therapeutic treatment of thrombi (blood clots) requires the release of anti-clotting agents near the blood clots; ${ }^{[7]}$ gene silencing therapies require the release of siRNA in the cellular cytoplasm where mRNA is translated into proteins; ${ }^{[8]}$ and inhibition of the overall cellular energy production requires the release of appropriate anti-cancer drugs in the mitochondria (i.e., the cellular power plants). ${ }^{[9]}$ To achieve effective drug delivery, it is important to first determine the activity of the drug in different cellular regions and secondly, to be aware of the variations within the cellular microenvironments. Such variations can be potentially exploited to engineer carriers with intelligent therapeutic release capabilities. 


\section{WILEY-VCH}

Extracellular drug release is important for the treatment of inflammation and thrombi. Strokes, pulmonary embolisms, and heart attacks are commonly caused by undesired formation of thrombi, which are the result of aggregated platelets. ${ }^{[7]}$ Thrombolytic drugs, such as urokinase, can effectively rupture and dissolve blood clots. However, urokinase typically prevents blood from clotting in other regions that can lead to a potentially fatal hemorrhaging when dosage is not carefully monitored. Thus, localized delivery of the thrombolytic agents, in close proximity to the undesired blood clots, has the potential to improve therapeutic outcomes. Similarly, the extracellular release of anti-cancer drugs in the vicinity of tumors is beneficial when multiple drugs are employed to provide different functions. One example is the combined use of an anti-cancer drug, such as doxorubicin (DOX), to directly kill cancer cells ${ }^{[10]}$ with an angiogenesis inhibitor, such as vascular endothelial growth factor receptor 1 (VEGFR-1), ${ }^{[11]}$ to inhibit the formation of blood vessels, hence inhibiting the supply of nutrients to the tumors.

For intracellular delivery, the localization of drug release from the therapeutic carriers is highly important. Anti-cancer drugs are a broad class of therapeutics that are active in different areas of cells depending on their mechanism of action. DNA intercalation and crosslinking drugs, such as $\mathrm{DOX}^{[10]}$ and cisplatin ${ }^{[12]}$ derivatives, are most effective when localized inside the nucleus, whereby they inhibit DNA replication. Other chemotherapeutic drugs, such as Gamitrinib, disrupt the mitochondrial membrane, and thus mitochondrial release is preferable. ${ }^{[9]}$ Other examples of therapeutics requiring mitochondrial release include antioxidants for Alzheimer's disease and uncouplers of oxidative phosphorylation for the treatment of obesity. ${ }^{[13]}$

The cytoplasm is the key target for the release of nucleic acids for siRNA gene silencing and peptides for vaccination. ${ }^{[14,15]}$ It is particularly important that these therapeutics are not 


\section{WILEY-VCH}

prematurely released within the acidic lysosomal compartments. The harsh lysosomal environment can effectively degrade peptides and nucleotides. Hence, premature release will significantly reduce therapeutic efficacy. Apart from the cytoplasm, the Golgi apparatus and endoplasmic reticulum (ER) are important release targets. Problems in the ER are the cause of the occurrence and development of a wide range of diseases including Parkinson's disease, and Type 1 and Type 2 diabetes. ${ }^{[16]}$ Golgi disorders are less prevalent, but as the factory for lysosomes, which play an important role in cellular processing, the Golgi becomes an important therapeutic target site.

There are three key changes within the cellular microenvironments that can be readily exploited for drug release: changes in the $\mathrm{pH}$, reduction/oxidation (redox) potential, and the presence and concentration of specific enzymes. Additionally, temperature-induced drug release has been extensively investigated. ${ }^{[17-19]}$ However, natural temperature fluctuations are typically insufficient to induce specific therapeutic release - external triggers, such as heat packs or light, are required. Such release mechanisms were featured in several recent reviews. ${ }^{[17-19]}$ In contrast, this review focuses solely on release mechanisms that rely on inherent triggers that are naturally present in biology.

\section{1. pH}

2.1.1. Extracellular $p H$. The $\mathrm{pH}$ of the extracellular environment is relatively consistent across various tissues and organs. In the blood and most organs, the $\mathrm{pH}$ ranges between 7.3 and 7.45. The main exception is the spleen ${ }^{[20]}$ which exhibits a $\mathrm{pH}$ of 7.2 for red pulp (which filters the red blood cells) and a $\mathrm{pH}$ of 6.8 for white pulp (which is a repository site for lymphocytes). It has been reported that in some hypoxic tumors, the $\mathrm{pH}$ can drop to a range of 6.4-6.8 $8^{[21]}$ due to the cancer cells metabolizing glucose via an anaerobic pathway which produces lactate. ${ }^{[22]}$ Thus, $\mathrm{pH}$ can be used as a trigger for inducing cargo release. The subtle 


\section{WILEY-VCH}

differences in the extracellular $\mathrm{pH}$ require the use of materials capable of responding to a narrow pH range. However, engineering polymeric carriers that can efficiently release their cargo at an appropriate $\mathrm{pH}$ while avoiding leakage within half a $\mathrm{pH}$ unit of the $\mathrm{p} K_{\mathrm{a}}$ of the polymer remains a challenge.

2.1.2. Intracellular $p H$. The intracellular environment is highly compartmentalized. Local environments can vary in $\mathrm{pH}$ from 4 to 8 , from oxidizing to reducing, and encompass a range of degrading enzymes. This range of environmental conditions emphasizes that it is critical to understand the conditions under which a therapeutic agent is active to ensure efficient targeted delivery. Additionally, it is important to analyze the internalization and trafficking mechanisms of the carriers. Understanding the microenvironment that the materials are exposed to provides a guideline to engineer carriers capable of responding to specific microenvironmental conditions where release of the cargo is required (Figure 1). 
WILEY-VCH

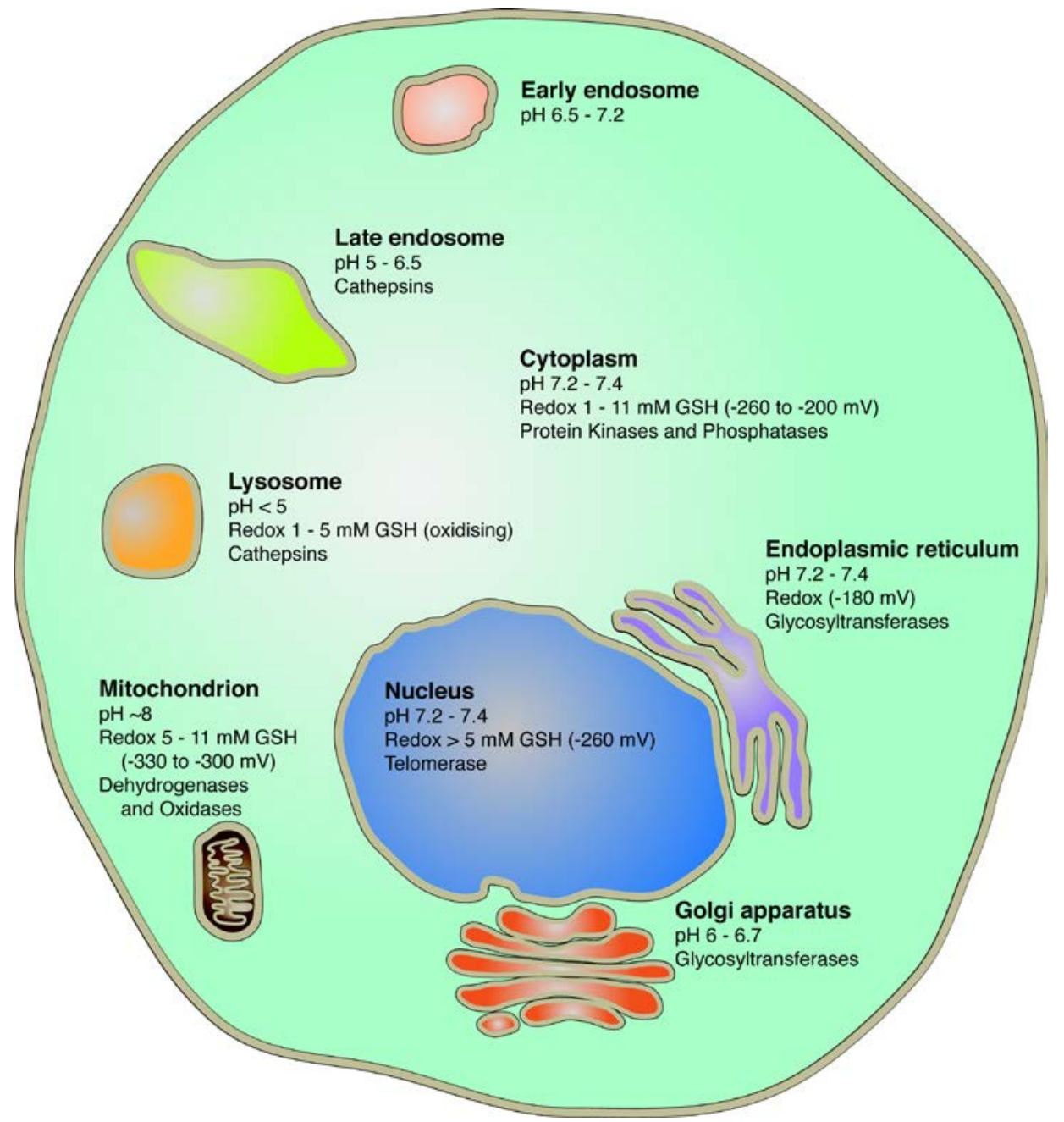

Figure 1. Schematic representation of diverse cellular microenvironments in terms of $\mathrm{pH}$ values, redox potential, and abundance of enzymes. Such features can be used for the rational design of triggered release systems. 


\section{WILEY-VCH}

The principal route for entry of materials into cells is via endocytosis. ${ }^{[23-25]}$ Invagination and budding of the cellular membrane are one of the key first steps in endocytosis, which is mediated by clathrin, caveolin, or clathrin/caveolin-independent pathways. ${ }^{[23-25]}$ Typically, internalization of carriers into endosomal compartments leads to rapid acidification of the compartments before fusion with lysosomes. ${ }^{[26]}$ The final $\mathrm{pH}$ of the endo/lysosomal compartments ranges between 4.5 and 5.5 depending on the cell type. Acidification occurs via proton pumps ${ }^{[27]}$ and channels ${ }^{[28]}$ that are associated with the endosomal membranes. To maintain a charge balance, counter ions, such as chloride, are additionally pumped into the endosomal compartments. Then, to maintain the osmotic pressure, water diffuses into the endosomes. In many instances, it is desirable for carriers to escape the endosomal compartments before they fuse with lysosomes. Thus, the active acidification process can be exploited in the material design. The proton sponge effect is a key endosomal escape mechanism that has been proposed in the literature. ${ }^{[29]}$ The proton sponge effect involves the use of a charged material, such as poly(ethylene imine) (PEI), that buffers the change in $\mathrm{pH} .{ }^{[28]}$ Cells continuously pump protons into the endosomes until the desired $\mathrm{pH}$ is achieved, leading to an increase in ionic strength and subsequent osmotic rupture of the compartments (Figure 2). ${ }^{[29,30]}$ Although the principle of such a technique is straightforward, in practice, the process of endosomal escape is significantly more complex because numerous polymers with $\mathrm{p} K_{\mathrm{a}}$ values between the physiological and lysosomal pHs do not exhibit endosomal escape. ${ }^{\text {[31] }}$ The actual mechanism ${ }^{[32]}$ may involve fusion between the materials and the endosomal membranes. Furthermore, the actual mechanism is highly dependent on the mechanism of endocytosis. A thorough understanding of the endosomal escape remains a key challenge for optimization of many therapeutic carriers, not only for achieving escape, but also for assessing the efficiency of the endosomal escape. Although it is likely that the uptake 


\section{WILEY-VCH}

mechanism affects the final fate of the cargo, a comprehensive understanding of this relationship is yet to be established.

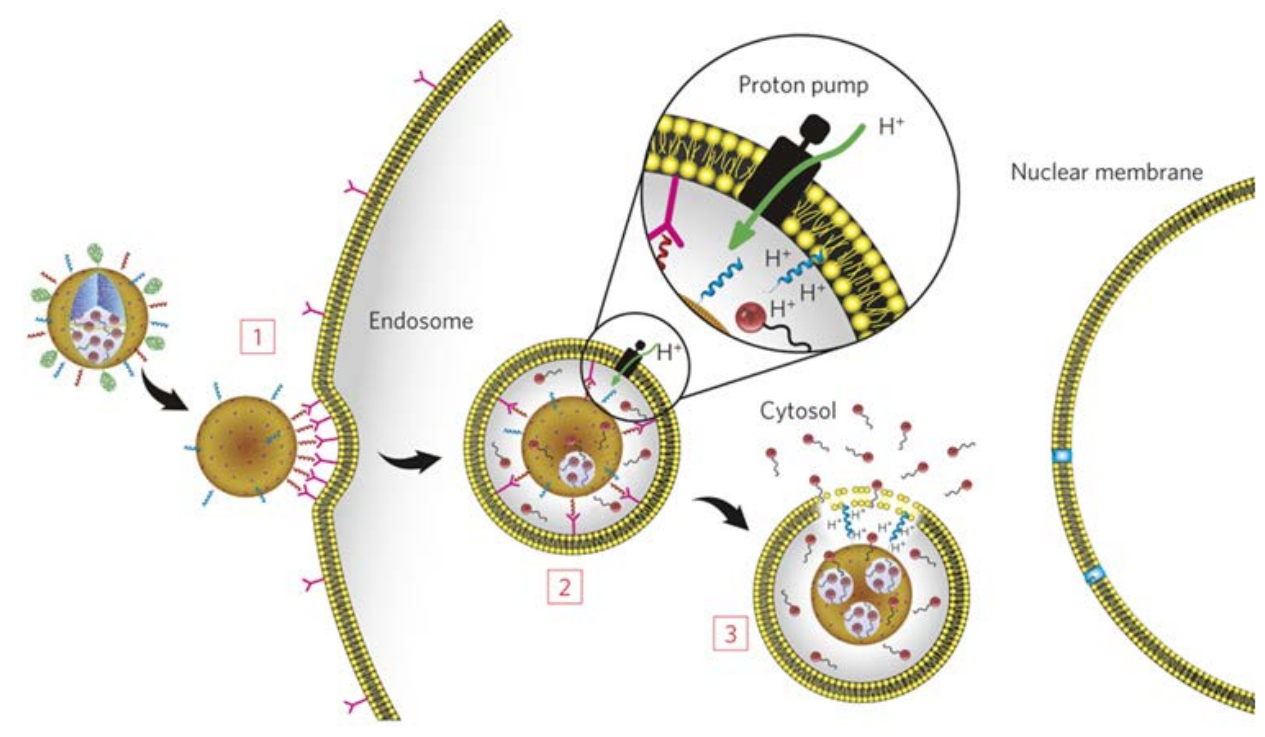

Figure 2. Illustration of the process of acidification during particle internalization and how this can be harnessed to achieve endosomal escape. (1) When a nanoparticle is endocytosed by a cell, the plasma membrane envelops the particle to form an endosomal compartment. (2) Proton pumps are recruited in the endosomal membrane; the protons are pumped across the membrane, leading to acidification of the endosome. To maintain charge balance, chloride ions are additionally pumped into the endosomal compartment. (3) Large amounts of protons and chloride ions pumped into the endosome can lead to osmotic swelling of the compartment, thereby inducing rupture of the endosomal membrane. Adapted and reproduced with permission. ${ }^{[30]}$ Copyright 2011, Nature Publishing Group.

In certain specialized cells, the acidification of endosomes occurs at a slower rate and to a lesser extent. ${ }^{[33]}$ This is particularly relevant for vaccine delivery, where dendritic cells (DCs) are the cells of interest. DCs have less acidic endosomes/lysosomes than other cells as acidification is suppressed by the presence of enzyme nicotinamide adenine dinucleotide 


\section{WILEY-VCH}

phosphate (NADPH) oxidase (NOX2). The NOX family of enzymes consumes protons to generate reactive oxygen species (ROS), such as hydrogen peroxide $\left(\mathrm{H}_{2} \mathrm{O}_{2}\right)$, ${ }^{[34]}$ which are used by DCs as the first line of defense to digest foreign materials. As a result, the $\mathrm{pH}$ of the endosomes of DCs typically remains above 7. In DCs, enzyme NOX2, which is a member of the NOX family, has been demonstrated to play a key role in the generation of ROS. ${ }^{[33]}$

If a polymeric particle escapes from the endo/lysosomal compartments, the principle therapeutic sites of action in the cell are the cytoplasm, nucleus, ER, Golgi apparatus, or mitochondrion. The cytoplasm, nucleus, and ER have similar pHs to that of the extracellular environment ( $\mathrm{pH} 7.4) .{ }^{[35]}$ The $\mathrm{pH}$ of the Golgi apparatus is slightly more acidic ( $\mathrm{pH} \sim 6.5$, whereas the mitochondrion is more basic $(\mathrm{pH} \sim 8) .{ }^{[35]}$ Harnessing these $\mathrm{pH}$ variations for carrier design has been an area of keen interest for many years. The recent literature in this area will be highlighted in Section 3.1.

\subsection{Redox Potential}

Reduction/oxidation (redox) potential measures the propensity of a molecule to gain (reduction) or lose (oxidation) electrons. Changes in the redox potential across different compartments of cells offer a convenient tool for triggering therapeutic release. For example, redox-active disulfide bonds can be incorporated into the material to stabilize the carrier or attach therapeutic molecules. In an oxidizing environment, disulfide bonds are stabilized, whereas in a reducing environment disulfide bonds are reduced to free thiol groups. In a simplified representation of the principle of such a release mechanism, disulfide exchange is mediated by tripeptide glutathione (GSH), which reduces the disulfide linkages in the material, subsequently releasing the therapeutic agent. However, actual redox reactions in cells are significantly more complex. 


\section{WILEY-VCH}

Redox reactions are ubiquitous in cells and play key roles in cellular processes. The reduction potential $(\mathrm{mV})$ of a compound is defined as its tendency to acquire electrons. Therefore, in a reaction, the reduction potential difference between two compounds is related to the free energy of a particular reaction. Thus, the greater the potential difference between the two compounds, the greater the tendency for the reaction to occur. Understanding the redox potential within a cell is challenging because it is difficult to directly measure the redox potential of specific compartments without affecting the redox state of the environment that is being measured. ${ }^{[36]}$ Alternatively, an approximation can be obtained by measuring individual redox reactions. Furthermore, owing to the nature of the cells, the latter are not in an equilibrium state, therefore leading to variations in their redox potential, consequently altering the existing redox state. Nevertheless, a general understanding of the redox potential within different cellular compartments can be achieved.

The redox potential within cells is strongly regulated as ROS, such as $\mathrm{H}_{2} \mathrm{O}_{2}$ and NO, can be highly damaging to normal cellular functions. GSH plays a dominant role in regulating the redox state of a cell and is involved in controlling protein folding - by regulating the formation and rupture of disulfide bonds - as well as reacting with excess ROS. As such, the concentration of GSH is often used as a representative measure of the cellular redox potential. GSH is one of the most highly abundant cellular metabolites, with an average cellular concentration between 5 and $10 \mathrm{mM} .^{[37]}$ The extracellular concentration of GSH is generally regarded to be lower than inside the cell, and as such the difference in redox potential is widely exploited as a release mechanism for when particles enter cells. However there are widely varying reports of blood GSH concentrations, with values reported as low as $10 \mu \mathrm{M}^{[38]}$ and as high as $1 \mathrm{mM} .^{[39]}$ The presence of reducing species in blood needs to be considered when designing drug carriers, and recent in vivo studies have show disulfide cleavage occurs in blood. ${ }^{[37]}$ The standard redox potential (E) between GSH and its oxidized form (GSSG) is 


\section{WILEY-VCH}

$-170 \mathrm{mV}$ at $\mathrm{pH}$ 7. However, the redox potential is highly dependent on the microenvironment $\mathrm{pH}$. The $E$ value increases by $5.9 \mathrm{mV}$ for every decrease in $\mathrm{pH}$ by 0.1 unit, thus indicating that in the acidic lysosomes, the reduction rate of disulfides related to GSH is significantly retarded. ${ }^{[40]}$

Besides the concentration of GSH, the amount of available GSH requires consideration. In an endosomal compartment with a diameter of $100 \mathrm{~nm}$, assuming a GSH concentration of $5 \mathrm{mM}$, only $1500 \mathrm{GSH}$ molecules are expected within a $5 \times 10^{-10} \mathrm{~nL}$ volume. This is important to consider when designing a release mechanism for polymeric carriers. GSH is not catalytic and is consumed during the degradation process. Hence, a $100 \mathrm{~nm}$ nanoparticle with a 5\% disulfide functionality will consume all GSH molecules typically contained within the endosome. A $100 \mathrm{~nm}$ particle features approximately 4000 disulfides assuming the concentration of the polymer is $5 \%(\mathrm{w} / \mathrm{w})$ relative to the hydrogel. Particles stabilized by disulfide groups will degrade relatively slowly as the GSH molecules are consumed and further degradation will be dependent on the accumulation of additional GSH molecules in the endosomal compartment or the regeneration of the oxidized GSH molecules by the enzyme glutathione reductase (Figure 3).

In addition to the presence of reducing species such as GSH, oxidizing species play a role in regulating the redox potential within cells. Monocytes and DCs use NOX to produce ROS that help to kill and digest materials that they phagocytose. ${ }^{[33]}$ This results not only in an increase in the redox potential, but also an increase in the $\mathrm{pH}$. In monocytes, the basic NOX oxidizing environment lasts for 15-30 min, but in DCs, NOX2 continues to mediate the endosomal compartments. ${ }^{[33]}$ A similar oxidizing environment is found in the mitochondria, where ROS are formed as by-products of energy generation. ${ }^{[41]}$ Disulfides have been incorporated into many polymeric carriers for therapeutic applications; however, carrier localization is an 


\section{WILEY-VCH}

important consideration to optimize such systems. Relevant literature in this area is highlighted in Section 3.2.
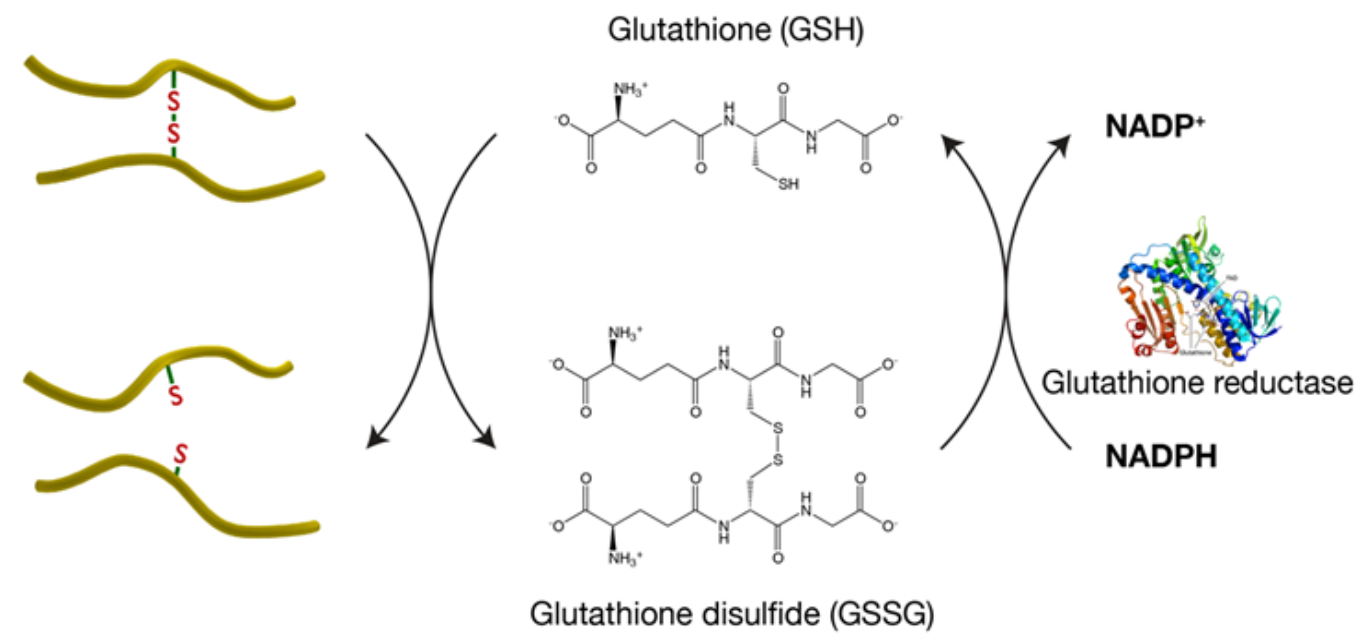

Figure 3. Schematic representation of the regeneration of glutathione (GSH) by glutathione reductase. Two GSH molecules are required to fully reduce a disulfide bond. The resulting oxidized GS-SG dimer is regenerated into two reduced GSH molecules by enzyme glutathione reductase in an energy-consuming process (NADPH is consumed in the regeneration process).

\subsection{Enzyme Concentrations}

Enzymes play fundamental roles in nearly all physiological processes including cell migration, angiogenesis, autophagy, apoptosis, and proliferation. An enzyme is termed after its substrates and the chemical reaction that it catalyzes. For instance, protease refers to the enzyme that catalyzes the cleavage of peptide bonds in a protein. In the past decades, our knowledge on enzymatic activities occurring in both physiological and pathological conditions has significantly developed, largely through transgenic/knock-out/knock-in animal models. It is now recognized that the dysregulation of enzymes is associated with the progression of many diseases. For example, several extracellular proteases are frequently overexpressed in cancer cells and/or tissues to facilitate tumorigenesis. ${ }^{[42]}$ Identification of an enhanced expression of 


\section{WILEY-VCH}

certain enzymes in tissue lesions is particularly important for advanced therapeutic delivery. Engineering carriers with components that can cleave by specific enzymes is an attractive approach for triggered therapeutic release. However, to date, such a degradation mechanism has received less attention than $\mathrm{pH}$ - and redox potential-mediated degradation mechanisms. To illustrate the potential in this area, several well-characterized enzymes, in particular upregulated enzymes in malignant tissues, and their extracellular and intracellular catalytic functionalities are reviewed.

2.3.1. Extracellular Enzymes. There is an increasing understanding of important extracellular markers for disease and these provide useful targets for polymeric carriers. An important example is thrombin that is associated with the formation of blood clots, and can cleave $\mathrm{N}$ terminal peptides from fibrinogen and cause the formation of insoluble fibrin. The thrombin cascade plays a significant role in maintaining hemostasis, whereby blood clotting, platelet activation, and vascular repair are strongly regulated to control the coagulation process. ${ }^{[43]}$ In the case of blood vessel wounds, the coagulation cascade is initiated by the release of tissue factors that convert prothrombin into thrombin. This process is followed by the activation of many clotting factors from their proenzyme to enzyme forms, ultimately leading to the formation of fibrin gel at the wound sites. The obstructed blood vessels result in higher shear stress, which has been exploited as a targeting mechanism to trigger shear-activated drug release. ${ }^{[4]}$ Alternatively, the atypical higher thrombin concentrations in blood clots - as a result of thrombosis that is a condition associated with blood clots that affects the normal blood flow - can be exploited as a release trigger for thrombosis-specific drug delivery. In a recent study, peptide-polysaccharide nanocomplexes that consist of cationic thrombincleavable peptides and heparin have been shown to release heparin (a widely used anticoagulant) at high concentrations of thrombin, effectively preventing thrombosis. ${ }^{[45]}$ 


\section{WILEY-VCH}

Matrix metalloproteinases (MMPs) comprise over 20 zinc-dependent proteases that can cleave the extracellular matrix (ECM) including collagens, glycoproteins, and proteoglycans. ${ }^{[46]}$ Some MMPs are secreted in the extracellular milieu, whereas other MMPs are membrane-tethered. Hence, MMPs not only degrade the ECM, but also the non-ECM substrates such as cell surface membrane proteins. The increased expression and activity of MMPs are frequently observed in diverse diseases such as cancer, ${ }^{[47]}$ inflammation, ${ }^{[48]}$ and cardiovascular diseases. ${ }^{[49]}$ In particular, several members of MMPs (i.e., MMP-2 and MMP9) have been associated with cancer cell invasion and metastasis because they degrade collagen and promote the spreading of tumors to surrounding tissues. This phenomenon is important for developing targeted tumor drug delivery. For example, peptides containing MMPs cleavage sequences can be designed to degrade carriers and release the therapeutic cargo.

In addition to the MMPs, secreted phospholipase A2 (sPLA2), which catalyzes the hydrolysis of lipids, is often significantly up-regulated in the extracellular microenvironment of tumors $^{[50]}$ and inflammatory tissues. ${ }^{[51]}$ In the presence of $\mathrm{Ca}^{2+}$, sPLA2 can hydrolyze cellular phospholipid membranes and other phospholipids such as lipoproteins, pulmonary surfactants, microbial membranes, and food substances. ${ }^{[52]}$ Therefore, sPLA2 has gained increasing interest as a physiological trigger in developing next-generation liposomes. For example, a recent study has compared the therapeutic activity of clinically used long-circulating (PEGylated) liposomes and sPLA2-responsive liposomes both in vitro and in vivo. ${ }^{[47]}$ The sPLA2-responsive liposomes resulted in 1.5 to 2-fold greater intracellular drug concentration when compared with the PEGylated liposomes, consequently leading to a significantly slower tumor growth in a mouse xenograft model. ${ }^{[53]}$ 


\section{WILEY-VCH}

2.3.2 Intracellular Enzymes. It is well understood that polymer delivery systems are commonly internalized through endosomal compartments. ${ }^{[54]}$ Thus, enzymes located in endo/lysosomal pathways represent another key enzymatic trigger for controlled release. However, there have been limited examples that successfully exploit intracellular enzymes for highly specific drug release. To date, most studies have been focused on lysosomal enzymes. Cathepsins are a class of proteases predominantly located in the endo/lysosomal vesicles. ${ }^{\text {[55] }}$ Some cathepsins, such as cathepsin B, are expressed in most cells and play important roles in protein turnover. ${ }^{[42]}$ Other types of cathepsins are produced by specific cells. For example, cathepsin S is only expressed in immune cells and participates in major histocompatibility complex (MHC) class II antigen presentation. ${ }^{[56]}$ As reported, cathepsins in tumor and tumorassociated cells are involved in the initiation and development of cancer and are highly upregulated in malignant tumors. ${ }^{[57]}$ Based on the location of specific cathepsins, therapeutic release can be designed either in the lysosomes or at the cell surface where cathepsins are expressed.

Degradation within the cytoplasm is important because it is the site of action for many therapeutics. Numerous enzymes have been observed in the cytoplasm. Protein kinases and phosphatases comprise a significant portion of cytoplasmic enzymes, but are also found at other intracellular sites. ${ }^{[58]}$ Kinases catalyze the transfer of phosphate groups from adenosine triphosphate (ATP) to the side chains of serine, threonine, and tyrosine residues in proteins, whereas phosphatases catalyze the dephosphorylation of proteins. ${ }^{[59]}$ The phosphorylationdephosphorylation serves as a molecular switch to mediate protein conformations, subsequently regulating diverse biological functionalities such as activation or attenuation of signaling pathways. ${ }^{[60]}$ It is estimated that up to $50 \%$ of all proteins is phosphorylated during their lifetime. ${ }^{[61]}$ There has been a wealth of evidence showing that elevated kinase expression levels and catalytic activities are strongly associated with the development of cancer and 


\section{WILEY-VCH}

metastasis. ${ }^{[62]}$ For example, intracellular tyrosine kinase c-Src and the protein kinase C family have been extensively studied because of their contribution to oncogenesis. ${ }^{[63]}$ Generally, overexpression of such protein kinases leads to increased cell proliferation and motility that is observed in many types of cancers such as breast, colon, lung, and ovarian cancer. ${ }^{[64,65]}$ In addition to the up-regulation, changes in the cellular location of kinases are an indicator of malignancy. For example, for the normal prostate epithelial cells, protein tyrosine kinase 6 (PTK6) is located in the nucleus; in contrast, this enzyme is present in the cytoplasm in the PC3 prostate cancer cell line and primary prostate tumors. ${ }^{[66]}$ Translocation from the nucleus to the cytoplasm of PTK6 decreases the constraints on cell proliferation in normal prostate cells and thus promotes cell survival.

A major function of the mitochondria is to produce ATP, the energy currency of a cell, to regulate cell growth, differentiation, and signaling. A considerable amount of data has shown that dysfunctional mitochondria are a key contributory cause to impaired heart efficiency ${ }^{[67]}$ and cancer. ${ }^{[68]}$ Dehydrogenases and oxidases that are localized almost exclusively in the mitochondria are involved in the conversion of energy into ATP via the citric acid cycle. ${ }^{[69]} \mathrm{A}$ pathological change occurring in many diseases (e.g., cancer) is manifested as a metabolic energy shift, resulting from a decreased concentration of dehydrogenases and an up-regulation of oxidases. ${ }^{[70-73]}$ For example, the family of NADPH oxidase enzymes is a predominant cellular source of ROS. ${ }^{[74]} \mathrm{NADPH}$ oxidase 4 (NOX4) is a major isoform primarily found in the mitochondria of cardiac myocytes. As demonstrated, the up-regulation of NOX4 increases ROS production, thereby enhancing oxidative stress and mediating cardiac dysfunction. ${ }^{\text {[75] }}$

Most glycosyltransferases involved in complex glycan biosyntheses are localized in the ER and Golgi apparatus, as these organelles are responsible for transporting and glycosylating newly synthesized proteins. ${ }^{[76]}$ These enzymes catalyze the attachment of $N$-glycans and $O$ - 


\section{WILEY-VCH}

glycans to a variety of proteins within the lumen of the ER-Golgi compartments. Glycosylation, one of the most abundant post-translational modifications of proteins, plays an important role in maintaining protein structure and promoting specific recognition by glycanbinding proteins, which has consequences in controlling cell-cell and cell-pathogen interactions. For instance, a number of cell adhesion molecules (e.g., E-cadherin) undergo complex $\mathrm{N}$-glycosylation mainly catalyzed by three glycosyltransferases (i.e., $\mathrm{N}$ acetylglucosaminyltransferase III (GnT-III), $N$-acetylglucosaminyltransferase V (GnT-V), and fucosyltransferase 8 (FUT-8)). ${ }^{[77,78]}$ It has been shown that an increase in the activity of GnT$\mathrm{V}$ leads to enhanced $N$-acetyl-D-glucosamine (GlcNAc) branching of $N$-glycan structures on cell adhesion molecules. $N$-Glycan branching has only been observed in malignant canine mammary tumor cells and remains absent in the benign phenotype. ${ }^{[79]}$ This observation suggests that the up-regulation of glycosyltransferases can be associated with the metastatic potential of tumors, thereby contributing to the spreading of cancer cells.

A wide variety of polymerases, exonucleases, and endonucleases exist in the nucleus. They work in concert to ensure genes are faithfully replicated and translated into proteins. ${ }^{[80]}$ Telomeres, which are located at the end of chromosomes, provide key signals for cell proliferation. ${ }^{[81]}$ In normal cells, the continuous chromosome replication results in progressive telomere shortening that subsequently induces senescence of the cells. ${ }^{[82]} \mathrm{A}$ mechanism to maintain the telomere length is through the action of telomerase, a reverse transcriptase that is a ribonucleoprotein containing both RNA and protein components. ${ }^{[83]}$ The protein component catalyzes the addition of a DNA sequence to the telomere region using the RNA component as a template. Owing to the activity of telomerase, the length of the telomere is restored during the telomere synthesis. In most human somatic cells, telomerase activity is negligible. However, telomerase up-regulation occurs in $85 \%$ of human cancer cells, and is a wellestablished hallmark of cell immortalization. 


\section{WILEY-VCH}

The examples highlighted above illustrate how biological enzymes can achieve targeted responses to their biological environment. In particular, Section 3.3 presents recent examples of polymeric carriers using bio-inspired components.

\section{Biologically Responsive Polymeric Carriers}

The synthesis of polymeric carriers with tunable properties such as size, surface chemistry, and morphology has been an area of interest for many decades. These carriers have been designed for application in diverse areas. Over the last decade, there has been significant progress in preparing polymeric carriers that can meet the complex biological requirements to achieve effective therapeutic delivery. The development of first-generation carriers was a steep learning curve for materials scientists to establishing and understanding the biological conditions that are required for specific therapeutic applications. Carriers, which are responsive to a simple trigger such as $\mathrm{pH}$ were the first developed, followed by the development of redox-responsive variants. $^{[3]}$ However, the incorporation of enzymeresponsive components has been slower to develop because of the specific knowledge requirements of the area. The following sections provide a summary of the pertinent recent studies. A solid groundwork of excellent past research studies has been provided elsewhere. ${ }^{[84]}$ External triggers, such as temperature, are also an important area of research that has additionally been comprehensively reviewed. ${ }^{[3,85]}$

\section{1. pH-Responsive Polymeric Carriers}

In this section, pH-responsive carriers are discussed. The carriers are divided into three categories based on the type of the $\mathrm{pH}$ responsive agent/process introduced into the carrier design: (i) pH-responsive polymeric building blocks; (ii) pH-responsive assembly; and (iii) 


\section{WILEY-VCH}

pH-responsive crosslinkers. Delivery systems that are responsive to multiple biological stimuli are also discussed.

3.1.1 pH-Responsive Polymers. The relevant $\mathrm{pH}$ range for designing materials that are responsive to cellular $\mathrm{pH}$ variations is 5-7. The exact desired $\mathrm{pH}$ range for triggering responses depends on the cargo within the carrier and its sensitivity. Generally, biological cargo should be released before drugs such as hydrophobic small molecules. pH-Responsive materials can be engineered using two approaches: (i) incorporating cleavable functionality within the polymer or (ii) incorporating responsive functional groups. A family of polymers that have responsive characteristics within a biologically relevant $\mathrm{pH}$ range is poly(2diethylamino ethyl methacrylate) (PDEAEMA) and related monomers. These polymers are hydrophobic when the amine groups are non-protonated and become positively charged when the $\mathrm{pH}$ is reduced to values below their $\mathrm{p} K_{\mathrm{a}}$. PDEAEMA has a $\mathrm{p} K_{\mathrm{a}}$ of $\sim 7$. The $\mathrm{p} K_{\mathrm{a}}$ of $\mathrm{pH}$ response can be tuned by using monomers with different substituents on the tertiary amine. A number of research groups have demonstrated the potential of PDEAEMA for cellular delivery. Irvine and coworkers reported the synthesis of polymer particles via emulsion polymerization using a PDEAEMA inner core cross-linked with poly(ethylene glycol dimethacrylate) (PEGDMA) and a pH-non-sensitive 2-aminoethyl methacrylate (AEMA) outer layer (Figure 4) ${ }^{[86]}$ Upon acidification, the particles underwent a 2.8-fold increase in particle size that corresponded to a 22-fold increase in volume. The cellular trafficking of the particles was additionally investigated to evaluate their endosomal escape capabilities. The escape was monitored using calcein, a small membrane impermeable dye, as an indicator. Calcein was co-delivered with either the responsive particles or the non-responsive control particles. Calcein fluorescence from the cells was only observed in samples with the responsive particles, which is indicative of endosomal escape events. 


\section{WILEY-VCH}

In a later study, Irvine and coworkers synthesized particles consisting of a poly $(\beta$-amino ester $)$ (PBAE) core and a phospholipid shell. ${ }^{[87]}$ The formulation was based on nanoprecipitation of the polymer-lipid blend from an ethanol solution into excess water. Similar to PDEAEMA, PBAE is insoluble at high $\mathrm{pH}$, but soluble in aqueous solutions below $\mathrm{pH}$ 7. It was shown that the particles rapidly disassembled under acidic pH. It was suggested that such rapid fragmentation would induce high osmotic pressures within the endosomal compartments, thereby leading to endosomal escape phenomena. To confirm the endosomal escape events, calcein was used as a small non-membrane permeable marker, as described earlier. Model mRNA was then loaded onto the surface of the particles. Interestingly, the RNA functionality was retained even though it was incorporated on the outside of the structure. It was also demonstrated that the particles were capable of transfecting DCs both in vitro and in vivo. A later study showed that the PBAE particles could be used to design a two-step delivery strategy, whereby a targeted immunotoxin was first added, followed by the addition of PBAE particles to facilitate endosomal escape of the therapeutics. ${ }^{[88]}$ The molecular weight cut-off of molecules that could be successfully released from the endosome using the polymer particles as a trigger was additionally examined. Both $3 \mathrm{kDa}$ and $10 \mathrm{kDa}$ dextrans showed efficient release when compared with the control (without polymer particles co-delivery). However, no differences in the release were observed for higher molecular weight dextrans. Additionally, Irvine and coworkers investigated an epidermal growth factor receptor (EGFR)-targeted gelonin toxin fusion protein (E4rGel), a $40 \mathrm{kDa}$ immunotoxin with an $\mathrm{IC}_{50}$ (half-maximal inhibitory concentration) of approximately $30 \mathrm{nM}$. When E4rGel was combined with the PBAE particles, a synergistic enhancement in the antitumor activity (over 50-fold improvement) compared with the individual components was observed. A similar system based on a poly( $\beta$-amino ester ketal) was developed by Almutairi and coworkers. ${ }^{\text {[89] }}$ The polymer is hydrophobic at neutral $\mathrm{pH}$, but becomes hydrophilic at a slightly acidic $\mathrm{pH}$ owing to the protonation of the amine groups within the structure. This $\mathrm{pH}$ change causes an increase 


\section{WILEY-VCH}

in hydration, enabling rapid hydrolysis of the polymer backbone. The polymer was used to synthesize particles using the double emulsion method in the presence of a model DNA cargo. A high percentage of Cy5-labeled (plasmid encoding green fluorescent protein) pEGFP DNA was loaded within the particle and the DNA was active and promoted significant fluorescence within the cells when compared with the control particles formed from poly(lactic-co-glycolic acid) (PLGA). Viger et al. demonstrated that these particles could be loaded with gadolinium (Gd) oxide nanoparticles and used as a MRI-responsive contrast agent. ${ }^{[83]}$ Limited contrast was observed when the particles were intact. However, when the $\mathrm{pH}$ decreased to below 6.5, the carriers degraded, subsequently releasing the Gd oxide nanoparticles that resulted in an order of magnitude increase in the MRI contrast. ${ }^{[90]}$

(a) $\mathrm{oH}$ insensitive

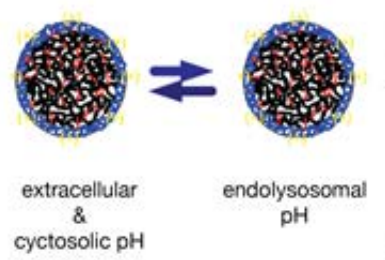

(e) $\mathrm{pH}$ sensitive
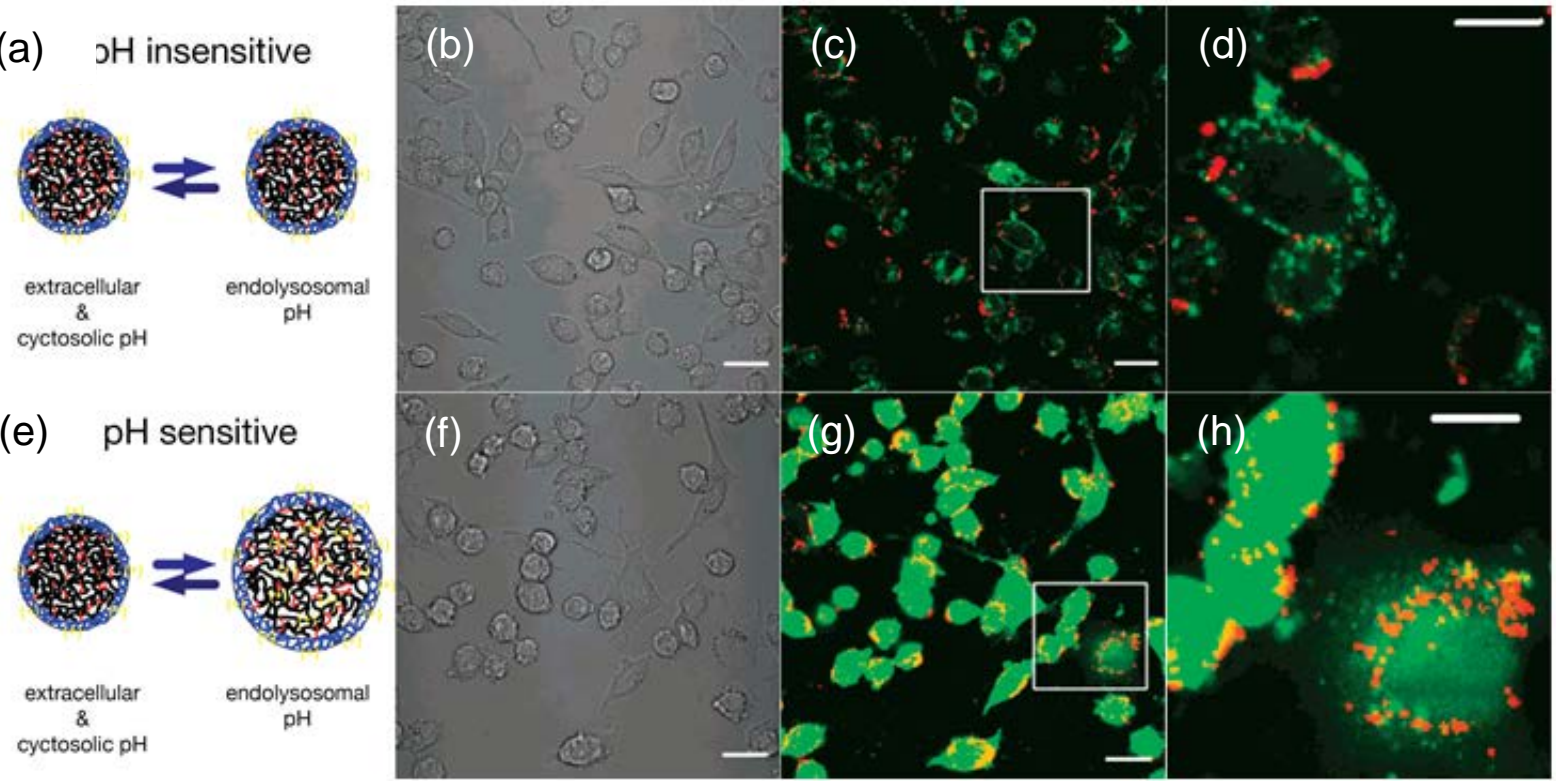

Figure 4. Particles with swelling properties can promote endosomal escape. (a-d) Nanoparticles that are not responsive to changes in $\mathrm{pH}$ remain in the endo/lysosomal compartments. Endosomal escape is assessed using calcein (green), which is endocytosed into the cells with the particles, but calcein remains in the endo/lysosomal compartments. (e-h) 


\section{WILEY-VCH}

Nanoparticles that swell owing to a drop in $\mathrm{pH}$ are able to rupture the endosomal compartments. The homogeneous distribution of calcein throughout the cell is indicative of escape. Scale bars are $20 \mu \mathrm{m}$ (b, c, f, g) and $10 \mu \mathrm{m}$ (d, h). Adapted and reproduced with permission. ${ }^{[86]}$ Copyright 2011, American Chemical Society.

In another study, Frechet and coworkers developed an interesting $\mathrm{pH}$-responsive polymer by modifying dextran with 2-methoxypropene to form a new water insoluble acetalated dextran (Ac-DEX). ${ }^{[84]}$ The modified polymer was used to prepare polymer particles using a double emulsion method. The resulting particles had a half-life of $\sim 15$ days at $\mathrm{pH} 7.4$, compared with $10 \mathrm{~h}$ at $\mathrm{pH} 5.0{ }^{[91]}$ A related study demonstrated the synthesis of a library of Ac-DEXs by changing the reaction time required to convert the dextran hydroxyl groups into the modified acetals. ${ }^{[92]}$ Degradation was tuned from $0.3 \mathrm{~h}$ (for fast degradation of Ac-DEX (f-Ac-DEX)) to $8 \mathrm{~h}$ (for slow degradation of variant (s-Ac-DEX)). The particles did not exhibit inherent endosomal escape capabilities; therefore, the efficiency of gene delivery was tuned by adding a PBAE-based copolymer. As observed, f-Ac-DEX achieved significantly higher transfection efficiency when compared with s-Ac-DEX. The superior performance may be due to the faster degradation rate, which was further enhanced by small loading of PBAE. However, a high loading ratio of PBAE led to an increased toxicity.

Polydopamine (PDA) materials have generated significant interest because of their ease of synthesis and strong interactions with various surfaces. However, PDA is well known to degrade slowly, thereby limiting its application in therapeutic delivery. Using simple and versatile building blocks, Cui et al. ${ }^{[93]}$ combined PDA with a thiol-modified poly(methacrylic acid) (PMA $\mathrm{PH}_{\mathrm{SH}}$ ) and an anti-cancer drug, doxorubicin (DOX), connected by pH-responsive hydrazine linkages. The conjugate was bound to PDA capsules via robust thiol-catechol reactions. The release studies demonstrated little release at neutral $\mathrm{pH}$, but over $85 \%$ at $\mathrm{pH} 5$. 


\section{WILEY-VCH}

Furthermore, $\mathrm{pH}$-responsive materials can be used as tunable surface coatings. A recent study used a PEGylated poly(2-2-aminoethyoxy)ethoxy phosphazene $\mathrm{mPEG}_{45}-b$-PAEP ${ }_{75}$-CyaDMMA (PPC-DA) ${ }^{[94]}$ The amide bonds of PPC-DA were stable at neutral $\mathrm{pH}$, but rapidly degraded under the slightly acidic $\mathrm{pH}$ of tumors, thereby exposing the positively charged amino groups. The block copolymer was associated with positively charged polyion complexes based on bio-reducible PEI and siRNA to form a pH-responsive outer coating. The multi-layered particles demonstrated an improved uptake under acidic $\mathrm{pH}$ when compared with both the control and non-responsive variants. This improvement was attributed to the positively charged surface. The enhanced uptake translated into an improved knockdown in vitro, but importantly, an improved inhibition of tumor growth in a murine model in vivo.

3.1.2. $p H$-Responsive Assembly. The design of $\mathrm{pH}$-responsive materials can also be achieved via self-assembly of a pH-responsive polymer. In such systems, the assembly into carriers is $\mathrm{pH}$ dependent; thus, upon a change in $\mathrm{pH}$, the $\mathrm{pH}$-responsive polymers will disassemble into unimers. Battaglia and coworkers demonstrated the $\mathrm{pH}$-responsive assembly using $\mathrm{pH}$ sensitive poly(2-(methacryloyloxy)ethyl phosphorylcholine)-co-poly(2(diisopropylamino)ethyl methacrylate) (PMPC-PDPAEMA) diblock copolymers - the latter copolymers self-assembled to form vesicles (i.e., polymersomes) (Figure 5). ${ }^{[95,96]}$ The polymersomes were stable at physiological $\mathrm{pH}$ upon deprotonation of the amine groups; however, they rapidly disassembled below $\mathrm{pH}$ 6. It was postulated that the instantaneous structural disassembly induced endosomal escape of the model cargo plasmid DNA (pDNA). The endosomal escape mechanism is similar to that proposed by Irvine and coworkers, as described earlier. Gao and coworkers conducted numerous related studies on pH-responsive micelles. They developed a tunable micelle using a series of diblock copolymers with a linear poly(ethylene glycol) (PEG) block and a tertiary amine-containing block. ${ }^{[97]}$ The $\mathrm{pH}$-induced 


\section{WILEY-VCH}

disassembly of the micelles was tuned by changing the substituents on the amine monomer at corresponding pHs from 7.5 to 5.5. To monitor cellular internalization, a fluorescent monomer was incorporated into the polymers. The fluorescent probe was quenched when the particles were intact, but was activated upon micelle disassembly. Another recent study involved the synthesis and assembly of PEG-co-PBAE micelles for use as in vivo probes. ${ }^{\text {[98] }}$ The disassembly of the micelles was tuned by changing the substituents on the PBAE chain, which directly influences the $\mathrm{p} K_{\mathrm{a}}$. It was demonstrated that these carriers could be co-loaded with a fluorophore-quencher pair, which showed little fluorescence in their assembled state. However, when the $\mathrm{pH}$ was reduced to values below the $\mathrm{p} K_{\mathrm{a}}$ of PBAE, the micelles disassembled, thereby generating a strong fluorescent signal. The versatility of these particles was demonstrated both in vitro and in vivo in 10 different mouse tumor models, showing a greater than 100-fold enhancement between the 'on' and 'off' fluorescent signals within 0.25 pH units. ${ }^{[99]}$ A related study investigated PDMAEMA- $b$-PDPAEMA micelles, which could be loaded with a model siRNA by complexation with the positively charged external polymer. The micelles could be co-loaded with amphotericin B (AmB), and incorporation of this molecule enabled tuning of the siRNA release from the endosomal compartments. ${ }^{[100]}$

a)
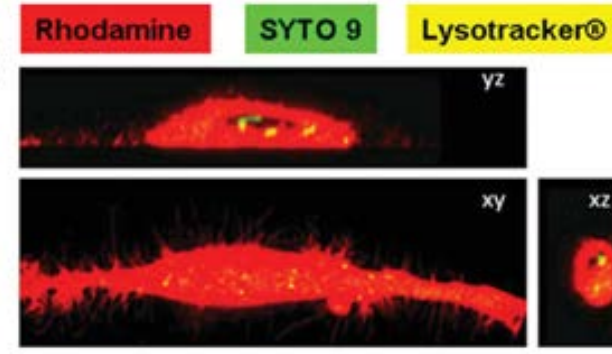

$$
\mathrm{pH} \text { sensitive polymersomes }
$$

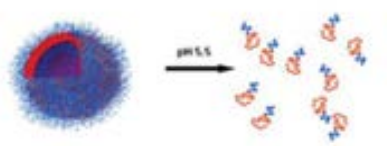

b)
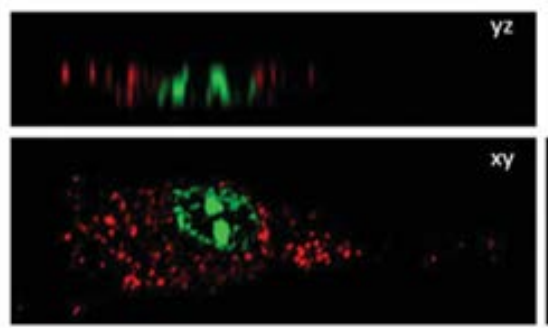

Non-pH sensitive polymersomes
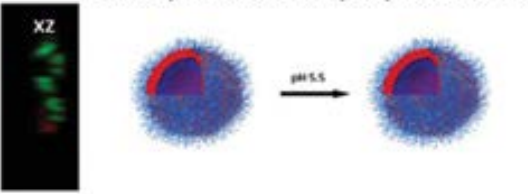


\section{WILEY-VCH}

Figure 5. Release of fluorescent cargo from pH-responsive polymersomes. (a) Confocal microscopy images show that rhodamine octadecyl ester perchlorate B (red) loaded into the pH-responsive PMPC-PDPA polymersomes is released from the polymersomes and escapes from the endosomal compartments. (b) pH-Insensitive PMPC-PDPA polymersomes loaded with the same cargo do not exhibit the same endosomal escape behavior. Images show cells treated with 200-nm polymersomes for 24 h. Lysosomes are stained with lysotracker (yellow) and DNA is stained with SYTO9 (green). Reproduced with permission. ${ }^{\text {[96] }}$ Copyright 2009, Wiley.

Recently Liang et al. investigated the synthesis of pH-degradable layer-by-layer (LbL) capsules based on PDPAEMA (Figure 6). ${ }^{[101]}$ This polymer is of interest because it is a member of the amine-based $\mathrm{pH}$-responsive family, as discussed earlier, with a $\mathrm{p} K_{\mathrm{a}}$ of $\sim 6.4$. PDPAEMA was used to assemble LbL capsules - PDPAEMA was first synthesized with a minor component of lauryl substituent $(10 \%)\left(\mathrm{C}_{12}\right)$ and then assembled in alternation with poly(methacrylic acid) (PMA) via a hydrogen bonding-based assembly process. At physiological $\mathrm{pH}$, both the PMA and template can be removed to generate stable PDPAEMA capsules owing to the $\mathrm{C}_{12}$ groups that serve as a hydrophobic stabilizer. Because of the hydrophobic nature of PDPAEMA at physiological $\mathrm{pH}$, the capsules shrank to less than half of their original size. In contrast, at $\mathrm{pH}$ values below the $\mathrm{p} K_{\mathrm{a}}$, the polymer became a hydrogel, and thus the capsules experienced a $300 \%$ increase in size. The considerable change in size and charge was used to retain small cargo, including peptides and small molecules. The cargo was efficiently released when the $\mathrm{pH}$ was decreased. A related nanoparticle system was additionally synthesized based on PDPAEMA particles stabilized by a poly(ethylene glycol)doxorubicin (PEG-DOX) conjugate. ${ }^{[101]}$ The particles formed upon precipitation of the polymer blend from ethanol in a phosphate buffered saline (PBS) solution. The particles degraded at pHs below 6.4, owing to the protonation of PDPAEMA. It was shown that a cell- 


\section{WILEY-VCH}

penetrating peptide could be loaded into these particles without affecting the particle properties. Additionally, the therapeutic efficacy was tuned by tailoring the amount of the incorporated peptide. ${ }^{[102]}$ In a related study, Liang et al. used PDPAEMA to design an endocytic capsule sensor. ${ }^{[103]}$ An alkyne-functionalized PDPAEMA (PDPAEMA ${ }_{\text {Alk }}$ ) was conjugated to a fluorophore (Alexa Fluor 488 (PDPAEMA Alk-488$\left._{3}\right)$ ) or a quencher (Black Hole Quencher 1 (PDPAEMA Alk-BHQ1)). The PDPAEMA $_{\text {Alk-488 }}$ and PDPAEMA ${ }_{\text {Alk-BHQ1 }}$ polymers were alternately assembled with PMA and cross-linked using a bis-azide PEG $_{12}$ linker to form polymer capsules. At neutral pH, PDPAEMA is hydrophobic, causing the adjacent PDPAEMA layers with either quencher or fluorophore to be in close proximity - hence, the sensor is 'off'. In contrast, at endosomal pH ( 6), the adjacent PDPAEMA layers repel each other because of the protonation of the amine groups, thus releasing the fluorophore from the fluorophore-quencher pairs - hence, the sensor is 'on'. The developed sensor was used to investigate the association and internalization kinetics of polymer capsules of different sizes.

(a)

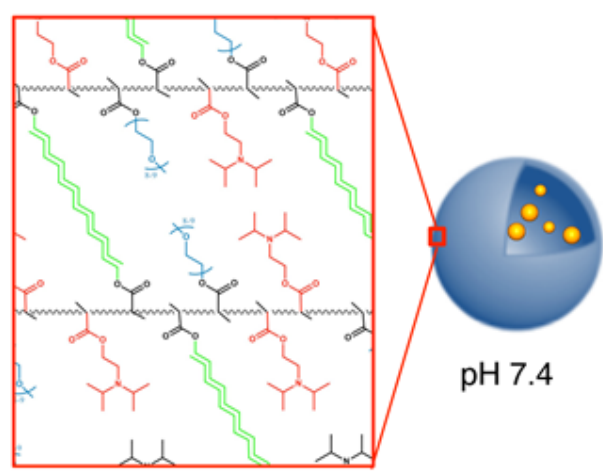

(b)

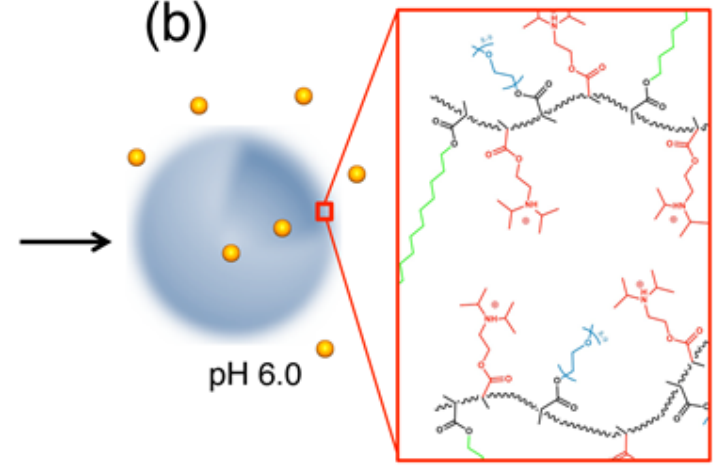

Figure 6. Schematic representation of (a) multilayered PDPAEMA capsules containing hydrophobic $\mathrm{C}_{12}$ groups (green) and DPAEMA groups (red) at $\mathrm{pH}$ 7.4. (b) Reducing the $\mathrm{pH}$ to below 6.4 to mimic endosomal $\mathrm{pH}$ conditions results in the protonation of DPAEMA, instigating charge repulsion among the polymer layers. This effect leads to rapid deconstruction of the capsules and release of therapeutics. Reproduced with permission. ${ }^{[101]}$ Copyright 2013, Wiley. 


\section{WILEY-VCH}

3.1.3. pH-Responsive Crosslinkers. A pH-responsive system can also be prepared by incorporating a pH-responsive crosslinker. Yan et al. recently developed a technique based on polymerization of an amine-rich polymeric shell around a protein (cysteine-alanine-serine; CAS) template stabilized by either the non-degradable crosslinker methylenebisacrylamide or the acid-degradable crosslinker glycerol dimethacrylate. ${ }^{[104]}$ CAS plays an essential role in apoptosis, necrosis, and inflammation. As demonstrated, CAS template proteins coated with a pH-responsive polymer layer significantly reduced cell proliferation when compared with the non-responsive variant. The same technique was applied to encapsulate a model siRNA cargo, CCr5, which is a major silencing target for HIV therapy (Figure 7). ${ }^{[105]}$ As a proof-of-concept, 293T cells were co-transduced with siRNA capsules and the plasmid expressing a fusion of CCR5 and mCherry reporter gene sequences. In the presence of serum, CCR5 nanocapsules successfully knocked down the expression of CCR5-mCherry to less than 15\%.
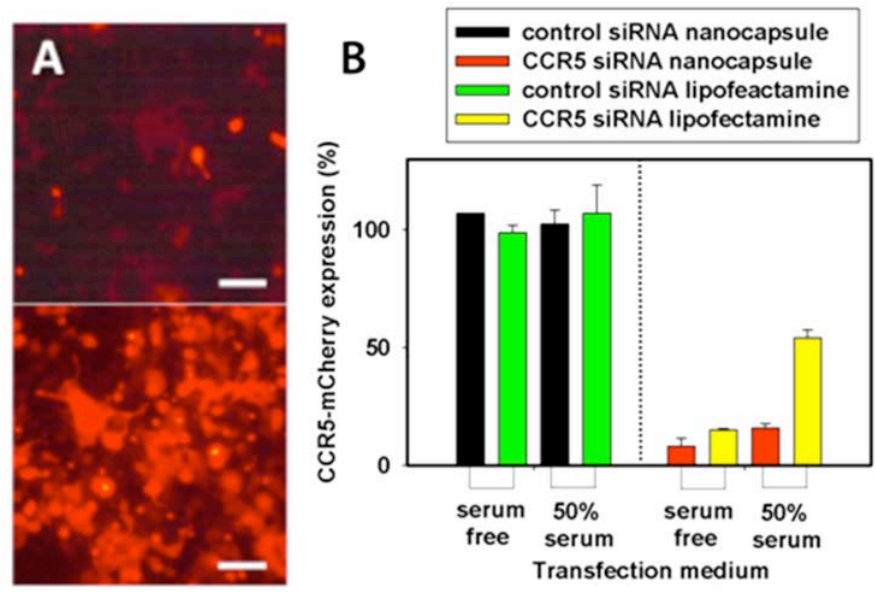

Figure 7. Knockdown of CCR5 RNA fused with mCherry in 293T cells using siRNA nanocapsules after 48 h. (a) Fluorescence images of 293T cells treated with CCR5 siRNA capsules (upper) and control nanocapsules (lower) in serum-free medium (scale bar is $10 \mu \mathrm{m}$ ). (b) Flow cytometry of HEK-293T cells treated with siRNA nanocapsules or siRNA lipofectamine complex in serum-free medium or $50 \%$ human serum medium. Cells were 


\section{WILEY-VCH}

treated with either siRNA nanocapsules or siRNA lipofectamine complex at $200 \mathrm{nM}$ for $4 \mathrm{~h}$ at $37^{\circ} \mathrm{C}$. Reproduced with permission. ${ }^{[105]}$ Copyright 2012, American Chemical Society.

3.1.4. Synergistic Response in Polymeric Carriers. Recently, there has been an increasing interest in incorporating multi-responsive capabilities into a carrier for improving the specificity of cargo release and/or carrier degradation. For instance, Liang et al. synthesized PDPAEMA capsules stabilized by a redox-active disulfide crosslinker. ${ }^{[106]}$ The capsules displayed high stability at physiological $\mathrm{pH}$, even in the presence of high amounts of GSH (5 $\mathrm{mM}$ ), but cleaved very rapidly at pH 6.0 even at low concentrations of GSH (0.1 mM). Subsequent studies demonstrated that the degradation of these systems could be tuned by adjusting the amount of crosslinker. ${ }^{[107]}$

Dai et al. combined $\mathrm{pH}$ and redox response features to create multi-responsive micelles. ${ }^{[108]}$ The carriers were based on a triblock copolymer of monomethoxy poly(ethylene glycol) (mPEG), 2-mercaptoethylamine (MEA)-grafted aspartic acid, and 2-(diisopropylamino) ethyl amine (DIP)-grafted poly(L-aspartic acid). The micelles were formed by self-assembly at $\mathrm{pH}$ 10, followed by interlayer cross-linking of the thiol functionalities to form disulfide bridges. DOX was loaded, and the DOX release kinetics from the carrier were examined. At $\mathrm{pH}$ 5, the structure was hydrated, owing to the pH-responsive core, enabling cargo release of $40 \%$. In contrast, at pH 5 and in the presence of dithiothreitol (DTT), a strong disulfide cleavage agent, cargo release from the capsules was $100 \%$.

\subsection{Redox-Responsive Polymeric Carriers}

Using redox-responsive components is a common strategy to design bio-responsive carriers. However, because the majority of drug carriers are internalized into acidic compartments within the cell, it is important to carefully design such carriers because redox-responsive 


\section{WILEY-VCH}

materials are less effective in such environments, as outlined in Section 2.2. Although oxidation of poly(ethylene glycol)-bl-poly(propylene sulfide) (PEG-PPS)-based polyersomes

to micelles has been explored for effective antigen delivery, ${ }^{[109,110]}$ the design of redoxresponsive polymeric carriers is largely based on the cleavage of disulfide bonds in the carriers. Certainly, a lower concentration range of the cleavage agent, such as GSH, provides a more realistic condition for degradation and release performance. In this section, redoxresponsive carriers are discussed and divided into two categories based on the incorporation of the cleavage site within the carrier design: (i) redox-responsive polymer building blocks and (ii) redox-responsive crosslinkers.

3.2.1. Redox-Responsive Polymers. Kataoka and coworkers have conducted studies using a diblock copolymer with a disulfide moiety in the center of the chain. ${ }^{[111]}$ As exemplified, two block copolymers, i.e., $\quad \operatorname{poly}(N$-(2-aminoethyl)-2-aminoethyl- $\alpha, \beta$-aspartamide) (PEG- $b$ PAsp(DET)) and poly( $\alpha, \beta$-aspartic acid) (PEG-SS-PAsp), were combined with a PAsp homopolymer to form polyion complex micelles (PICM). ${ }^{[111]}$ The micelle structure was tailored by adding DTT, which led to partial cleavage of PEG on the surface. Furthermore, the micelle size, upon disulfide cleavage, could be tuned by adjusting the ratio of the homopolymer to PEG-SS-PAsp within the carrier. The same group additionally designed a LbL system with a disulfide-cleavable block copolymer, i.e. PEG-SS-PAsp(DET), as the terminal layer. ${ }^{[112]}$ This polymer was chosen because of the proton sponge properties of PAsp(DET) and the stealth capabilities of PEG. Successful knockdown of luciferase expression was observed in siRNA-loaded carriers. This knockdown was enhanced in the carrier containing PEG-SS-PAsp(DET) relative to the control sample with no disulfide moieties. 


\section{WILEY-VCH}

Particle replication in non-wetting templates (PRINT) is an important particle fabrication strategy, which has demonstrated high versatility, including capabilities to tune size, shape, and rigidity. ${ }^{[113]}$ For example, DeSimone and coworkers investigated the gene expression efficiency of a siRNA-loaded material by preparing a siRNA monomer containing a cleavable disulfide component. ${ }^{[114]}$ The monomer was copolymerized in an amine-based polymer formulation. Then, the knockdown capability of the loaded siRNA toward luciferase expression was investigated. Efficient luciferase knockdown was only observed in the reactive siRNA particles, whereas control samples containing either non-cleavable siRNA or scrambled siRNA showed minimal knockdown effects (Figure 8).
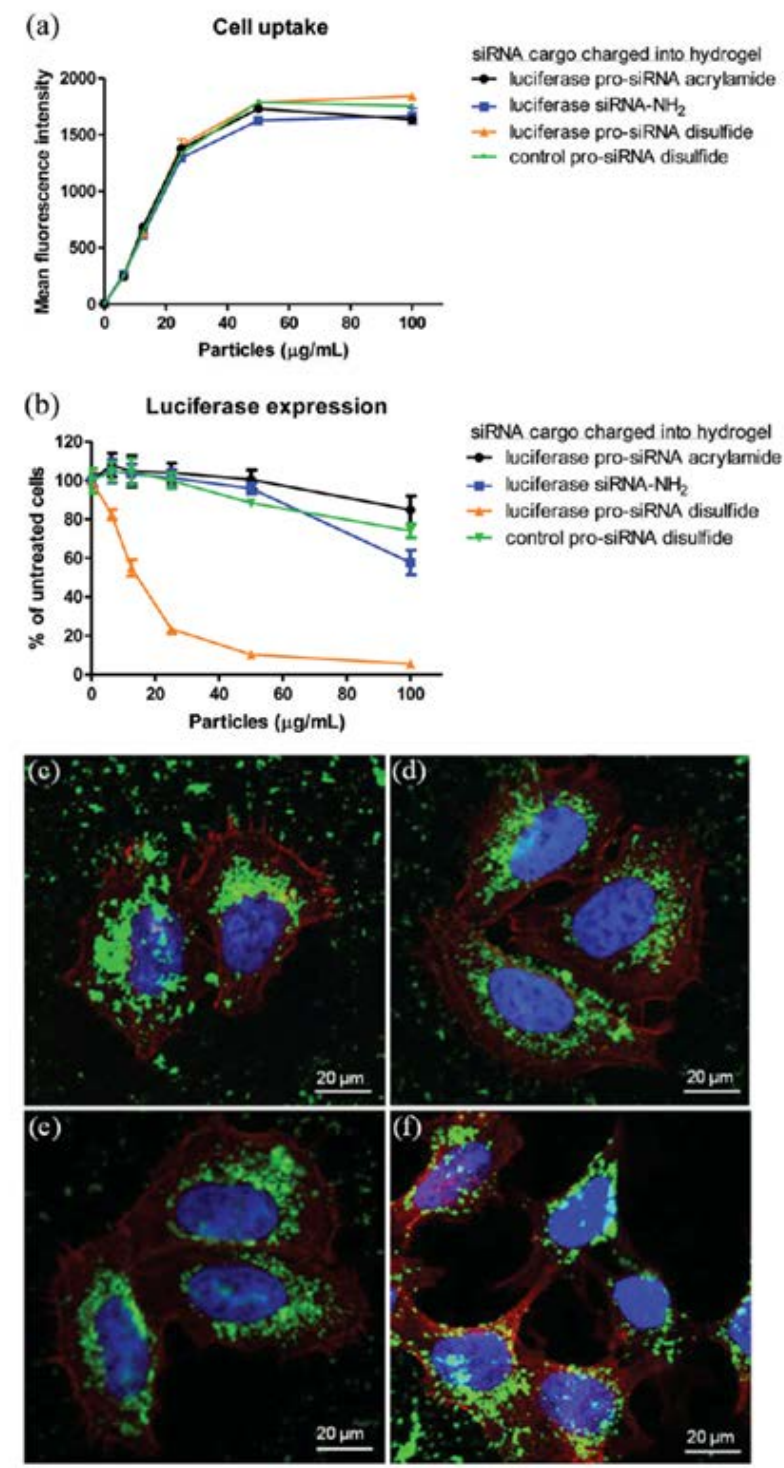


\section{WILEY-VCH}

Figure 8. PRINT hydrogel particles based on 30\% 2-aminoethyl methacrylate hydrochloride formulation were designed with different pro-siRNA cargos for transfection of HeLa cells including (1) luciferase pro-siRNA disulfide, (2) control pro-siRNA disulfide, (3) native luciferase siRNA with no conjugation, and (4) luciferase pro-siRNA with a non-degradable linkage. (a) Cellular uptake - HeLa/luc cells were incubated with particles for $4 \mathrm{~h}$ - followed by trypan blue treatment and flow cytometry analysis. (b) Luciferase expression. Cells were incubated with particles for $4 \mathrm{~h}$ then washed and incubated for $48 \mathrm{~h}$ in media. Experiments were conducted in triplicate. All hydrogels were thoroughly washed after synthesis to remove unbound siRNA. (c-f) Confocal micrographs. HeLa/Luc cells were loaded with $50 \mu \mathrm{g} / \mathrm{mL}$ hydrogels containing (c) luciferase pro-siRNA disulfide particles, (d) native luciferase siRNA, (e) non-degradable luciferase pro-siRNA particles, or (f) conjugated control siRNA particles. Reproduced with permission. ${ }^{[114]}$ Copyright 2012, American Chemical Society.

Another redox-responsive LbL system has been developed based on the assembly of PMA $\mathrm{SH}_{\mathrm{H}}$ in alternation with poly( $N$-vinyl pyrrolidone) $(\mathrm{PVPON})$ via hydrogen bonding. ${ }^{[15]}$ The $\mathrm{PMA}_{\mathrm{SH}}$ layers were cross-linked by oxidation of the thiol functionalities, and the sacrificial template and PVPON were subsequently removed to form single-component, stable microcapsules. Decreasing the amount of thiol resulted in an increase in the degradation rate of the capsules in simulated cellular conditions (5 mM GSH). ${ }^{[116]}$ Related studies demonstrated that these carriers could be used for loading and release of small drugs, proteins, and DNA cargo. ${ }^{[117]}$ Kempe et al. reported the fabrication of redox-responsive, low fouling LbL polymer capsules based on thiol-containing poly(2-ethyl-2-oxazoline) (PEtOxMA $\mathrm{SH}_{\text {) }}$ brushes, which were assembled in alternation with poly(methacrylic acid) (PMA) via hydrogen bonding. ${ }^{[118]}$ An elevated temperature was used to cross-link the PEtOxMA $\mathrm{SH}_{\mathrm{SH}}$ layers, and subsequent sacrificial template and PMA removal yielded microcapsules. Complete in vitro capsule degradation in simulated cellular conditions (5 mM GSH, $\mathrm{pH} 5.9,37^{\circ} \mathrm{C}$ ) was 


\section{WILEY-VCH}

achieved after $2.5 \mathrm{~h}$. The responsive nature of the capsules was further investigated using a vaccine model cell line (JAWS II); the capsules degraded intracellularly after $24 \mathrm{~h}$.

3.2.2. Redox-Responsive Crosslinkers. Using redox-responsive crosslinkers is a simple and tunable method to incorporate redox-responsive functionalities. Extensive studies on the design of LbL delivery systems using such crosslinkers have been conducted. Earlier studies involved modifying PVPON with alkyne functionalities and subsequent assembly with PMA via hydrogen bonding interactions. The layers were subsequently stabilized by a disulfidecontaining bis-azide crosslinker. At neutral $\mathrm{pH}$, the hydrogen bonding interactions were disrupted, leading to the removal of PMA, consequently generating redox-responsive PVPON capsules. ${ }^{[119]} \mathrm{Ng}$ et al. demonstrated that the capsule degradation and release rate of plasmid DNA (loaded as a model cargo into the hollow capsule core) could be tuned by changing the length of the crosslinker. ${ }^{[120]}$ Furthermore, excess alkyne groups within the structure could be used to modify the surface, for example, with functional antibodies. The synthesis of other types of polymer capsules, including poly(ethylene glycol acrylate)-based capsules, has also been demonstrated using the same approach. ${ }^{[121]}$ Additionally, redox-responsive cross-linking was used to form polymer-coated protein particles by interfacial polymerization on a protein surface using a series of amine monomers and a disulfide crosslinker $N, N^{\prime}$ bis(acryloyl)cystamine. ${ }^{[122]}$ Mature caspase 3, which is a serine protein that causes rapid cell apoptosis, was used as a model protein. To assess the activity of the encapsulation and release of caspase 3, a colorimetric assay employing a CP-3 peptidyl substrate mimic, Ac-DEVDpNA ( $p$-nitroanilide), was used. In the absence of GSH, no caspase 3 activity was observed, indicating efficient protection of the protein by the surrounding polymer shell. However, in the presence of GSH, caspase 3 activity increased. It was found that $2 \mathrm{mM} \mathrm{GSH}$ over $1 \mathrm{~h}$ was sufficient to degrade the polymer shell. The caspase 3 activity was additionally investigated 


\section{WILEY-VCH}

by evaluating cell apoptosis induced by either the degradable or the non-degradable variant.

Significant cell apoptosis was only observed in the disulfide-cleavable variant.

There is growing interest in using peptide-based materials to design carriers due to the materials inherent biocompatibility. Star polymers with a redox-responsive core were recently developed using amino acid building blocks. ${ }^{[123]}$ Ring-opening polymerization of a $\varepsilon$-Z-Llysine $N$-carboxy anhydride (NCA) was used to form poly( $\varepsilon$-Z-L-lysine) that served as arms. Subsequent addition of L-cystine NCA, which acted as a crosslinker, resulted in the formation

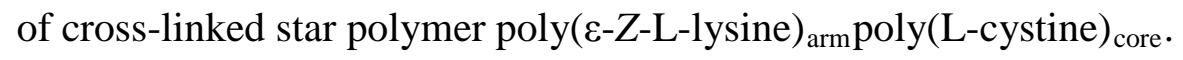

Several research groups have synthesized polymer nanoparticles with a crosslinkable component within the polymer backbone. One recent study demonstrated the formation of particles based on PEG-poly(2-(hydroxyethyl) methacrylate-co-acryloyl carbonate) (P(HEMA-co-AC)). The copolymers were prepared with different numbers of AC units and then cross-linked by ring opening with cystamine. The resulting particles demonstrated high stability at neutral $\mathrm{pH}$, but degraded in the presence of high levels of DTT $(10 \mathrm{mM}) .{ }^{[124]}$ Zhang et al. developed a related system based on PEG-b-poly(5-(4-(prop-2-yn-1yloxy)benzyl)-1,3-dioxolane-2,4-dione) (Tyr(alkynyl)-OCA); the latter was cross-linked using click chemistry with a mixture of crosslinkers with and without a disulfide group. ${ }^{[125]}$ As expected, degradation in the presence of DTT could be tuned by adjusting the amount of the responsive crosslinker in the system.

\subsection{Enzyme-Responsive Polymeric Carriers}

Biodegradability is one of the important aspects to consider when designing materials for advanced biomedical applications, particularly for therapeutic delivery and tissue engineering. This attribute minimizes undesirable interactions among residual foreign materials within the 


\section{WILEY-VCH}

body, as well as eliminates the necessity of material removal. Natural variations inside the cells can be used to design intelligent carriers with built-in triggers that are capable of responding to biological stimuli. Examples of cellular variations include $\mathrm{pH}$, redox potential, and the presence of enzymes. For instance, cancerous tumors or inflamed tissues display more reducing $^{[126,127]}$ and/or more acidic $^{[128,129]}$ environments relative to normal tissues. Furthermore, the different types of tissues, cells, and cellular compartments comprise varying types of enzymes depending on their biological functions. Interestingly, the healthy or unhealthy state of tissues or cells additionally influences the concentration and type of enzyme. Thus, this variation can potentially be used as a targeting tool to specific cells or specific cellular compartments. Using enzyme-responsive materials is of great interest owing to their (i) catalytic property, (ii) high selectivity, (iii) high activity under mild conditions, and (iv) role in governing the healthy and diseased biological pathways. ${ }^{[130,131]}$ Hence, the integration of enzyme-sensitive materials into the design of carriers can potentially allow for excellent spatial control over cargo release at the target sites.

Enzyme-responsive carriers can be designed based on peptides, lipids, or polynucleotides. ${ }^{[132]}$ To date, the most widely studied enzymes are phospholipases, ${ }^{[133,134]}$ cancer-associated proteases (CAPs), ${ }^{[135]}$ kinases, ${ }^{[136,137]}$ and acetyltransferases. ${ }^{[138]}$ This section particularly focuses on enzyme-responsive carriers that are sensitive to proteases. A genetic study revealed that approximately $2 \%$ of the human genome contains genetic codes for proteases that have crucial roles in regulatory pathways. ${ }^{[139]}$ Thus, proteases are useful prognostic indicators and specific targets for therapeutics. Protease sensitivity can be introduced into carriers by the use of polypeptide or peptide containing tailored amino acid sequence with enzyme-specific recognition sites. The use of peptide itself is highly versatile owing to its small size, ease of scale-up, simplicity for conjugation, and low cytotoxicity. ${ }^{[135]}$ Peptides can be integrated as therapeutic agents in the fabrication of carriers, building blocks, targeting 


\section{WILEY-VCH}

molecules, substrates for a specific enzyme, or cell-penetrating peptides (CPPs) to facilitate therapeutic delivery. ${ }^{[135,139-149]}$ The interesting field of CPPs application has been comprehensively discussed therein. ${ }^{[150-154]}$ The current review focuses on peptide-based carriers that can respond to specific enzymes owing to the high specificity of such materials. The peptide-based carriers are divided into three categories based on the functionality of the peptide incorporated into the carrier design: (i) as enzyme-responsive components, (ii) as enzyme-responsive spacers in the polymers, and (iii) as enzyme-responsive crosslinkers.

3.3.1. Peptides as Carrier Building Blocks. Poly(L-glutamic acid) (PGA) has been widely used to fabricate biodegradable carriers for drug delivery systems. ${ }^{[155]}$ The development of a PGA-paclitaxel conjugate has extended to clinical trials. Owing to the enzyme-based degradability of PGA, paclitaxel was slowly released at physiological pH (up to 14\% over 24 h), arguably because of random enzymatic hydrolysis. ${ }^{[156]}$ In the presence of cathepsin $\mathrm{B}$, the release of paclitaxel increased because of the PGA backbone degradation following endocytic uptake. ${ }^{[156,157]}$ In vivo experiments on cathepsin B homozygous knockout mice indicated the important role of this enzyme in governing the polymer-drug conjugate degradation. ${ }^{[157]}$ Polymer conjugates are an important research field and other relevant examples can be found in these reviews. ${ }^{[157,158]}$ Similar PGA-based materials have been used to design particulate carriers. For instance, Tansey et al. synthesized star-shaped particles comprising multibranched PGA chains on either the poly(amidoamine) (PAMAM) dendrimers or the PEI cores. ${ }^{[159]}$ These star particles incorporated folic acid as a model targeting moiety and nearinfrared dye indocyanine green as a model diagnostic agent - incorporation was achieved by chemical conjugation to the terminal amino groups and side chain carboxyl groups of branched PGA, respectively. Successful folate conjugation was confirmed by enhanced targeting capabilities of the particles toward folate-overexpressing tumor cells. Carrier degradation, as enabled by the biodegradable PGA building blocks, was investigated in the 


\section{WILEY-VCH}

presence of lysosomal cathepsin B enzyme $(\mathrm{pH} 5)$. The observed in vitro degradation correlated to the number of PGA arms and time taken for degradation: i.e., $137 \mathrm{~h}$ for PAMAM $_{8}$-PGA and $20 \mathrm{~h}$ for PAMAM 16 -PGA.

Stupp and coworkers exploited protein kinase A (PKA), ${ }^{[160]}$ which is a ubiquitous enzyme and a known extracellular biomarker for cancer, ${ }^{[161-163]}$ as an enzyme-specific trigger to induce cargo release and degradation of peptide amphiphilic (PA) nanostructures (Figure 9). Webber et al. fabricated PA nanostructures using KRRASVAGK[C $\left.{ }_{12}\right]-\mathrm{NH}_{2}$ (PA1), with PKA-specific recognition sequence RRXSO, where $X$ refers to an amino acid residue. ${ }^{[160]}$ The intramolecular $\beta$-sheet hydrogen bonding among the amino acid residues within the PA nanostructures provided structural stability. Upon PKA treatment, phosphorylation of serine residues in PA1 (to form PA2) caused degradation of the PA nanostructure because of the disruption of the intramolecular $\beta$-sheet hydrogen bonding. Interestingly, upon treatment with alkaline phosphatase (ALP), serine in PA2 was dephosphorylated and PA2 was reverted to PA1. The substrate-enzyme specificity of the PA carrier was verified using two separate control experiments: (i) treatment of the PA1 nanostructures with protein kinase B (PKB) and (ii) assembly of the PA nanostructures using non-responsive PA (KRRSAVAGK[C $\left.{ }_{12}\right]-\mathrm{NH}_{2}$ ) (PA3). Additionally, model drug DOX was encapsulated into the PA1 carriers and the DOX release was investigated. Upon PKA treatment, the release of DOX from PA1 was similar to that of the free drug. In contrast, negligible DOX release was observed in the systems of PA1 in the absence of PKA and PA3 in the presence of PKA. These results demonstrated the specific correlation between the enzyme (PKA) and the substrate (PA1). Webber et al. additionally conducted in vitro experiments using three different cell lines, i.e., immortalized breast cancer cells MDA-MB-231, 3T3 mouse fibroblast, and human umbilical vein endothelial cells (HUVECs). 3T3 and HUVECs were used as controls. Total death of the MDA-MB-231 cells was observed upon addition of PA1, whereas negligible cell death was 


\section{WILEY-VCH}

observed for both 3T3 and HUVEC. The in vitro experiment further confirmed the substrateenzyme specificity of PA1-PKA.

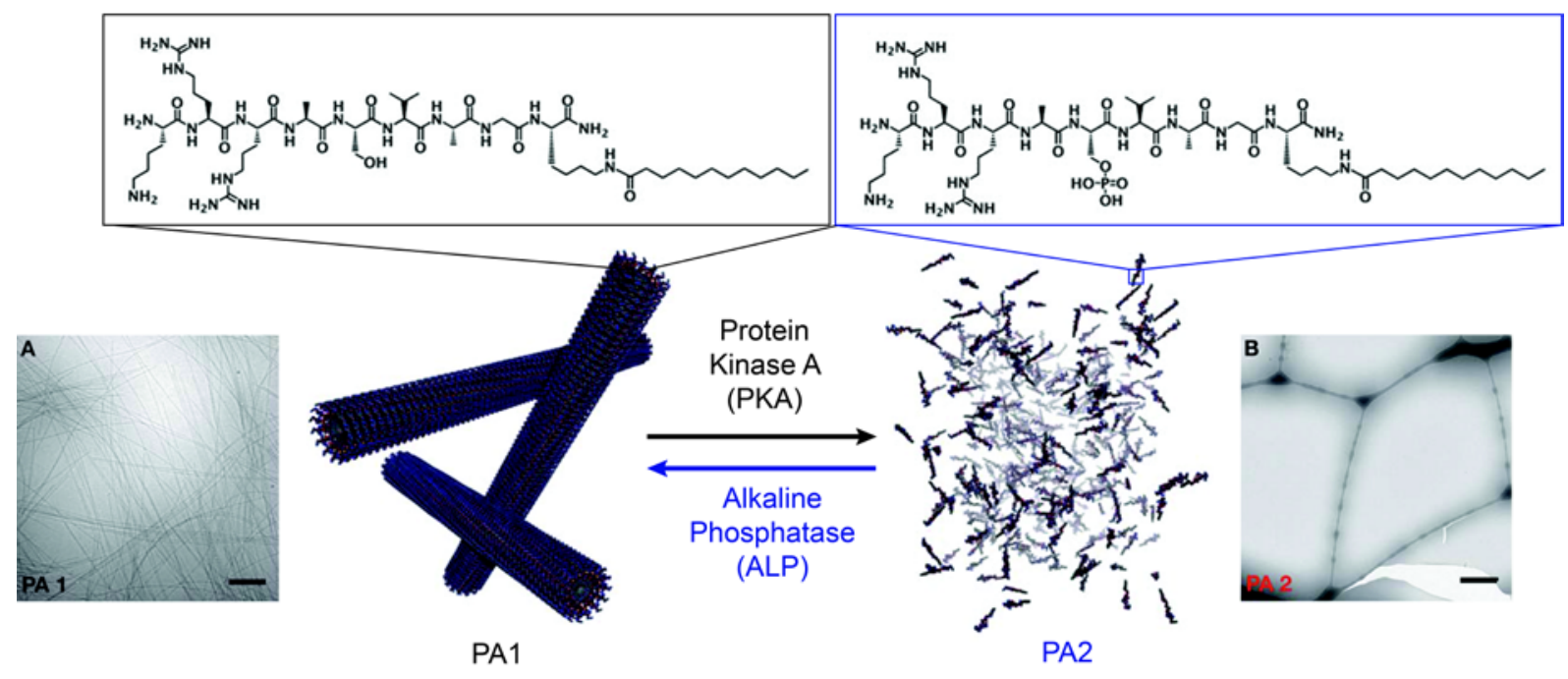

Figure 9. Schematic representation of the disassembly of PA1 upon treatment with protein kinase A (PKA) to form PA2 and its reassembly upon treatment with alkaline phosphatase (ALP). Cryogenic transmission electron microscopy (Cryo-TEM) images of (a) PA1 and (b) PA2. Scale bars are $200 \mathrm{~nm}$ (A) and $500 \mathrm{~nm}$ (B). Adapted and reproduced with permission. ${ }^{[160]}$ Copyright 2011, The Royal Society of Chemistry.

MMP-responsive micelle systems have shown promise for use in cancer treatment. Pluronic ${ }^{\circledR}$-based micelles are of particular interest for the following reasons: (i) they have reached Phase II clinical trials, ${ }^{[164]}$ (ii) they have demonstrated capabilities toward sensitizing multi-drug resistant cells and increasing drug transport across cellular barriers, ${ }^{[165]}$ and (iii) they have thermo-responsive properties. ${ }^{[166]}$ Garripelli et al. designed bi-responsive micelles based on a multi-block copolymer consisting of Pluronic ${ }^{\circledR}$ and an MMP-2-cleavable peptide (GPVGLIGK). ${ }^{[166]}$ The micellar thermogels were designed to self-assemble at physiological 


\section{WILEY-VCH}

$\mathrm{pH}$ and undergo enzymatic hydrolysis in the presence of MMP. The enzymatic drug release rate was investigated by conjugating paclitaxel. Complete degradation was achieved after $24 \mathrm{~h}$.

In another example, Lecommandoux and coworkers reported the synthesis of enzymeresponsive nanoparticles susceptible to degradation by MMP-2. ${ }^{[167]}$ The hybrid nanoparticles were formed by precipitating a poly(trimethylene carbonate) (PTMC) peptide hybrid that contained a PVGLIG peptide sequence, which was susceptible to cleavage by MMP-2. In the presence of MMP-2, the nanoparticles degraded over a 48-h period. In contrast, particles prepared in the absence of a MMP-2-cleavable peptide sequence remained stable.

Furthermore, Caponi et al. ${ }^{[168]}$ reported that phosphatases could be useful for inducing the self-assembly of micelles. The micelles were designed to have dual-responsive capabilities based on thermo-responsive poly(2-isopropyl-2-oxazoline) (PiPrOx) and enzyme-responsive fluorenylmethyloxycarbonyl tyrosine (Fmoc-Y). ${ }^{[30]}$ The hybrid polymeric-biomolecular system was obtained by a copper(I)-catalyzed azide-alkyne cycloaddition (CuAAC) reaction between $\alpha$-alkyne-terminated PiPrOx and Fmoc-pY-azide to form Fmoc- $p Y$-PiPrOx. Phosphatase treatment instigated dephosphorylation of Fmoc-pY-PiPrOx into Fmoc-YPiPrOx that either shrunk or swelled when the temperature was respectively set to above or below the lower critical solution temperature (LCST) of PiPrOx. The size of the micelles upon temperature switch varied by up to a factor of 4 relative to the original size.

3.3.2. Peptides as a Spacer in Polymeric Systems. Enzymatic responses can also be incorporated into a drug carrier using peptide spacers. Conventional polymer-drug conjugates are mostly connected using enzyme-labile linkages. ${ }^{[169-172]}$ However, using such a linkage is non-ideal because existing steric hindrance in these conjugates limits enzyme accessibility toward the substrates that subsequently becomes the rate-determining step for degradation. ${ }^{[173-}$ 


\section{WILEY-VCH}

${ }^{175]}$ Therefore, peptide spacers serve as good alternatives because their length can be tuned for regulating the degradation kinetics. ${ }^{[176]}$ Furthermore, spacers are commonly designed to be self-immolative, and are thus removed upon trigger action. ${ }^{[177]}$

Peptide spacers have been used to fabricate various scaffolds, such as hydrogels, ${ }^{[178,179]}$ polymeric photosensitizer prodrugs, ${ }^{[180]}$ and on-demand cleavable radioimmunoconjugates, ${ }^{[181]}$ for tissue engineering and therapeutic targeting applications. Studies have been performed on the influence of peptide length on the therapeutic efficacy of a polymer-drug conjugate system ${ }^{[182]}$ and on the importance of specific recognition sequences to optimize enzymatic cleavage. ${ }^{[183]}$ These studies indicate the growing interest in harnessing naturally occurring enzymes for fabricating new 'smart' biomedical devices.

One of the most extensively studied polymer-drug conjugate systems is based on poly( $N$-(2hydroxypropyl)methacrylamide) (PHPMA) featuring a cathepsin B-cleavable tetrapeptide spacer (GFLG) ${ }^{[184,185]}$ Cathepsin B is a ubiquitous enzyme that predominantly localizes in the acidic cellular compartments. ${ }^{[57,186-190]}$ Thus, the incorporation of this spacer into a carrier system is of interest as it can cleave upon carrier internalization via endocytic pathways. ${ }^{[191]}$ Studies have shown that the ideal molecular weight of PHPMA is $~ 30 \mathrm{kDa}$ for optimal endocytosis $^{[192]}$ and biodistribution. ${ }^{[193,194]}$ This molecular weight ensures that HPMA clearance occurs after cargo release. Regardless of the use of targeting ligands, the optimum drug loading required for enhancing anti-tumor activities of the therapeutic agent was evaluated as $10 \mathrm{wt} \% .{ }^{[195]}$ HPMA-GFLG-DOX is the first synthetic polymer-drug conjugate carrier that reached Phase I and Phase II clinical trials. ${ }^{[158]}$ The conjugate demonstrated partial responses in breast and non-small cell lung (NSCLC90) cancers, but minimum response in colorectal cancer. ${ }^{[157,185]}$ Apostolovic et al. ${ }^{[196]}$ developed a HPMA-based system with a bioinspired coiled E3/K3 heterodimeric peptide spacer. The design of E3/K3 was based on the 


\section{WILEY-VCH}

ubiquity of the coiled conformation in biological motifs, thereby offering a possibility for enhanced intracellular transport and trafficking. Interestingly, the spacer undergoes structural changes (folded to unfolded) at endosomal $\mathrm{pH}$ that facilitates endosomolytic degradation. ${ }^{\text {[197] }}$

Etrych et al. extended the use of HPMA to design a star polymer system. ${ }^{[198,199]}$ The star polymer consisted of PHPMA-DOX arms on a PAMAM dendrimer core. Carrier degradation was observed after $72 \mathrm{~h}$ upon exposure to cathepsin $\mathrm{B}^{[198]}$ and up to several days in vitro inside EL4 T-cell lymphoma cells. ${ }^{[199]}$ Shankar et al. examined a PAMAM-GFLG dendrimer system to design a drug carrier for 2-methoxyestradiol (2ME), which is an anti-proliferative and anti-angiogenic drug with poor water solubility and pharmacokinetics properties. ${ }^{[200]}$ Positively and negatively charged dendrimers were synthesized by modifying the end groups with amine (amine-functionalized star-shaped peptidic macromolecules (ASPM)) and carboxyl (carboxyl-functionalized star-shaped peptidic macromolecules CSPM) moieties, respectively. CSPM showed greater stability (100\% over $24 \mathrm{~h})$ and a faster degradation rate (100\% degradation over 2 h) when compared with ASPM (50\% stability over 24 h; 100\% degradation over $24 \mathrm{~h}$ ). The different degradation kinetics were attributed to the core-tosequence or sequence-to-core linkage on the PAMAM dendrimer core. The CSPM variant was subsequently chosen for conjugation with 2-ME. Upon conjugation, the solubility of 2ME improved by 26-fold while maintaining the anti-proliferative and anti-angiogenic activity. Additionally, this carrier reduced the metabolism of 2-ME, hence providing a better in vivo profile such as increased circulation time and tumor accumulation.

Another peptide (GFLGF) with a cathepsin B recognition sequence was integrated into polymersomes comprising (mPEG)-GFLGF-poly(D,L-lactide) (PDLLA). ${ }^{[201]}$ Self-assembly of the polymer was achieved using a solvent exchange technique. The polymersomes had an average hydrodynamic diameter of $124 \mathrm{~nm}$ and a membrane thickness of $15 \mathrm{~nm}$. In the 


\section{WILEY-VCH}

presence of cathepsin B, the polymersomes gradually degraded over 7 days. An increased degradation rate was achieved at higher enzyme concentrations, suggesting the possible association of this peptide on the polymersome membrane. The integration of a targeting moiety, an anti-epidermal growth factor receptor (anti-EGFR) antibody, resulted in a higher cellular uptake upon $3 \mathrm{~h}$ of incubation with SKBR3 cells.

Shabat and coworkers synthesized the first generation of self-immolative dendrimers with drugs conjugated to the tails of an enzyme-cleavable (catalytic antibody 38C2) dendrimer core. ${ }^{[202]}$ The dendrimer core, known as the focal point, was designed to be sensitive to the retro-aldol-retro-Michael cleavage reaction. Therefore, different anti-tumor drugs (e.g., DOX, camptothecin, and etoposide) could be simultaneously conjugated to the dendrimer and subsequently released via a single enzymatic cleavage mechanism, thereby showing the potential of this carrier for overcoming resistance to several drugs. ${ }^{\text {[203] }}$

Owing to limited work on the use of peptide components in polymer carriers, we have highlighted some examples of liposome studies. Biomimetic liposomal systems are one of the most developed systems in therapeutics delivery because of their minimal accumulation in the heart, kidney, and nervous system. ${ }^{[204]}$ To fabricate novel enzyme-active liposomes, Pak et al. conjugated a $N$-acetyl-AA peptide sequence to 1,2-dioleoyl-sn-glycero-3phosphoethanolamine (DOPE). ${ }^{[205]}$ The resulting conjugate $N$-Acetyl-AA-DOPE when combined with trimethylammonium propane (DOTAP) and phosphatidylethanolamine (PE) formed non-fusogenic liposomes. However, upon treatment with elastase or proteinase $\mathrm{K}$, the liposomes became fusogenic. This system is of potential use for anti-tumor drug delivery as elastase is produced in breast ${ }^{[206]}$ and skin ${ }^{[207]}$ cancers. 


\section{WILEY-VCH}

Furthermore, Hashida and coworkers developed enzyme-active liposomes. ${ }^{[208]}$ A hepatocellular carcinoma (HCC)-specific MMP2 recognition sequence (GPLGIAGQ) was incorporated into the system as a targeting moiety. The peptide sequence was linked to PEG and then conjugated to DOPE to form PEG-PD. Then, PEG-PD was conjugated to galactosylated liposomes to form Gal-PEG-PD liposomes. In normal cells, PEG is expected to impart stealth capabilities into the liposome though this PEG shielding effect would be lost upon exposure to MMP2-producing cells owing to peptide cleavage. The presence of the shielding-deshielding effect was confirmed by the higher cellular uptake in MMP2expressing cells. The higher cellular uptake was attributed to the exposure of the galactose targeting functionality upon PEG layer release, thereby inducing carrier internalization via asialoglycoprotein receptor-mediated uptake. Pretreatment of the Gal-PEG-PD liposomes with a conditioned medium of mouse melanoma cells (B16BL6), which actively secrete MMP2, showed enhanced binding to HepG2 cells. Furthermore, the improved delivery was due to the increased cytotoxicity of $N^{4}$-octadecyl-1- $\beta$-D-arabinofuranosylcytosine (NOAC) upon treatment with human purified MMP (hMMPs) at a low concentration (5 $\mu \mathrm{g} / \mathrm{mL})$.

3.3.3. Peptides as a Linker in Polymeric Carrier Systems. The incorporation of enzymespecific peptide sequences as a spacer into polymer-drug conjugate systems has shown promise in governing carrier degradation and/or cargo release. Recently, Gunawan et al. ${ }^{[209]}$ has extended this concept to design enzyme-responsive LbL carriers. The system comprised enzyme-degradable inner multilayers and an outer pH-sheddable coating. The inner multilayers were fabricated using charge-shifting PDPAEMA, containing alkyne moieties, which were cross-linked using a bis-azide crosslinker. Enzymatic degradability was achieved by incorporation of the cathepsin B-cleavable sequence (GFQGVQFAGF) into the crosslinker. The outer coating was assembled using an amphiphilic PDPAEMA diblock copolymer (POEGMA-b-PDPAEMAPA), which was stabilized via hydrophobic interactions with 


\section{WILEY-VCH}

PDPAEMA in the inner multilayers and hydrophobic amino acids within the peptide sequence. The outer coating conferred colloidal stability to the particulate carriers and provided protection for the enzyme-labile components within the inner multilayers, but was released upon exposure to endo/lysosomal pH. Upon release of the outer coating, the cathepsin Bsensitive crosslinker was exposed, thus enabling carrier degradation via enzymatic hydrolysis. Degradation occurred rapidly (within $10 \mathrm{~min}$ ) in vitro inside JAWS II cells, employed as a model vaccine cell line.

Thornton et al. developed enzyme-responsive hydrogel particles using amino-functionalized poly(ethylene glycol acrylamide) (PEGA) with peptide sequences for charge-induced swelling and enzyme-triggered cargo release (Figure 10). ${ }^{[210]}$ Three different peptide sequences, Fmoc-DAAR-PEGA, Fmoc-RRAADD-PEGA, and Fmoc-DGGR-PEGA, were designed and their degradation kinetics were compared. The overall enzymatic hydrolysis for the different peptide sequences varied depending on the overall charge of the peptide. The charge-shifting capabilities were governed by the number of arginine moieties within the peptide sequences. Consequently, the hydrogels were stable at physiological $\mathrm{pH}(\mathrm{pH}>5)$ and provided excellent cargo encapsulation. However at $\mathrm{pH}<5$, the particles swelled and cargo release was triggered by enzymatic degradation and charge repulsion among the arginine moieties. Another type of enzyme-degradable PEG-based particles were fabricated using poly(ethylene glycol diacrylate) (PEGDA) integrating an acylated peptide (GFLGK-diacrylate). ${ }^{[211]}$ This system comprised particles of $50 \mathrm{~nm}$ in diameter that were degraded in the presence of cathepsin B. 


\section{WILEY-VCH}

A

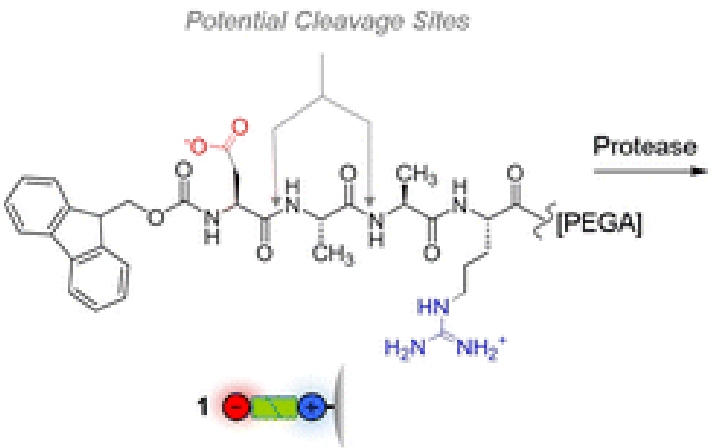<smiles>CC(NC(=O)C(CO)NC(=O)OCc1cccc2ccccc12)C(=O)O</smiles><smiles>CC(N)C(=O)NC(CCNN)C(=O)C(C)C(N)=O</smiles>

B

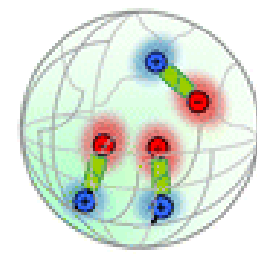

PEGA Particle

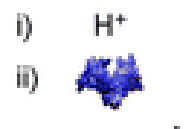

iii) $\mathrm{OH}$

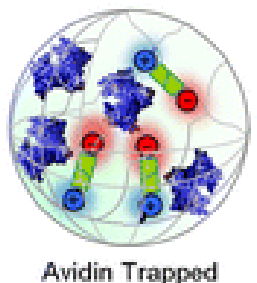

Protease
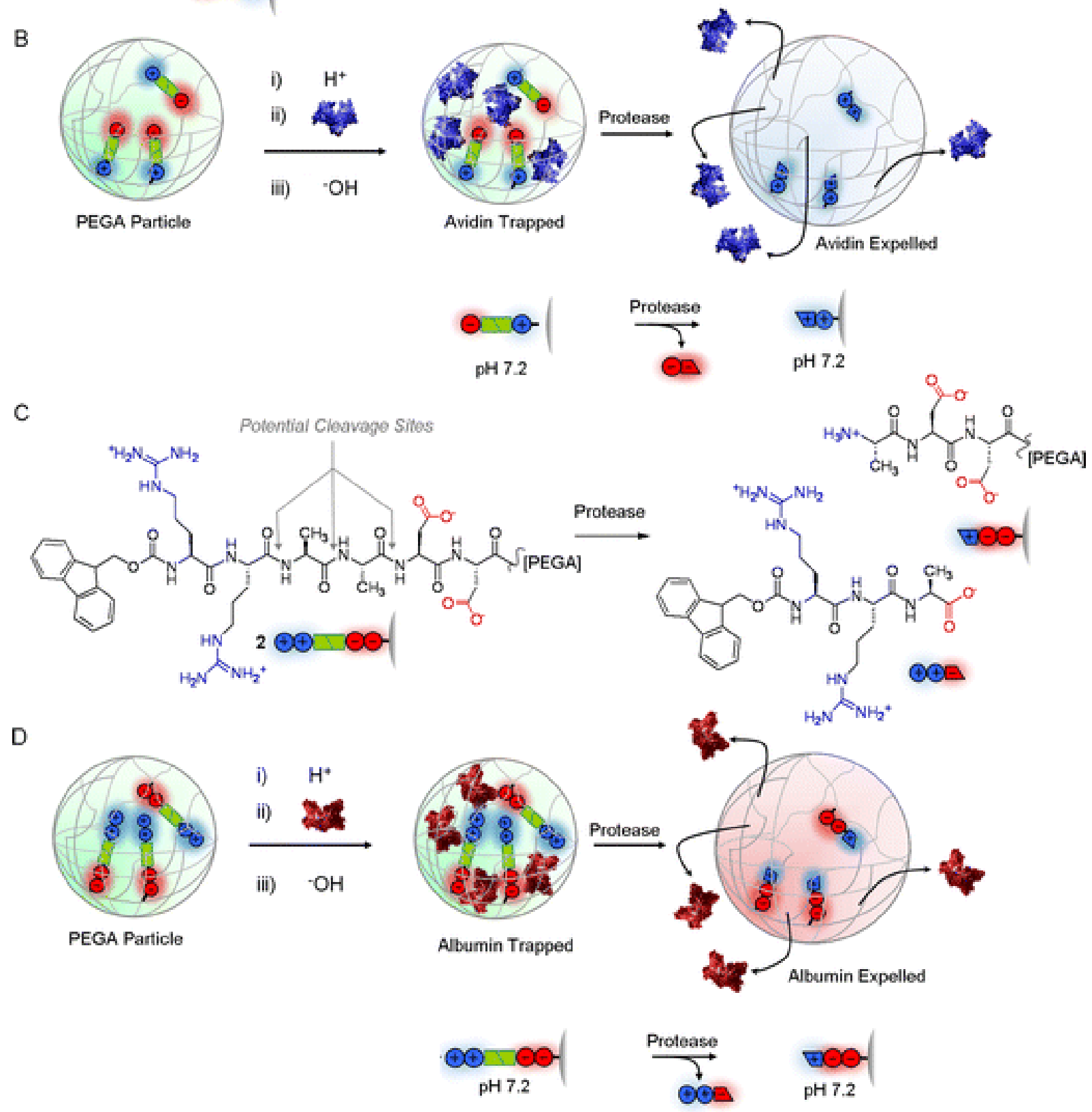

Figure 10. Schematic of enzyme-induced release of (a, b) positively and (c, d) negatively charged proteins from nanoparticles. (a) To facilitate the release of positively charged proteins, an Fmoc-aspartatic acid-alanine-alanine-arginine-cleavable peptide is attached to the particle. In the presence of the cleavage enzyme, the zwitterionic peptide splits into two, 


\section{WILEY-VCH}

leaving a positively charged peptide attached to the particle. (b) When a positively charged protein is loaded into the particle, the peptide is cleaved. The nanoparticle then becomes positively charged, thus leading to the release of the cargo owing to electrostatic repulsions between the cargo and particle. (c) To facilitate the release of negatively charged proteins, the particles are functionalized with a peptide containing two N-terminal arginine units separated from two aspartic acid groups by two alanine residues. (d) When a negatively charged protein is loaded into the particle, upon peptide cleavage, the nanoparticle becomes negatively charged, thus releasing the cargo. Reproduced with permission. ${ }^{[210]}$ Copyright 2008, The Royal Society of Chemistry.

\section{Future Perspectives}

The field of biomedicine is an exciting new frontier for polymeric carriers. Over the last ten years, there has been significant progress in the ability to precisely engineer material properties and architectures using facile coupling techniques such as click chemistry. These new tools combined with the versatile nature of polymeric building blocks have allowed the development of a broad range of polymeric carriers, which can respond intelligently to biological stimuli. Further progress has been achieved over the past several years on the efficacy of such carriers to respond to specific biological conditions, as evidenced from the extension of proof-of-concept studies to in vivo and clinical trials. However, despite such progress, thorough understanding of interactions between cells and polymeric carriers is yet to be achieved. Knowledge in this area is limited to specific carriers achieving a therapeutic outcome, such as knockdown or drug release, rather than comprehensively identifying the mechanism of cell trafficking of different particles and the efficiency of cargo release. For many of these fundamental questions, such as the mechanism and efficiency of endosomal escape, we are still limited by current analytical tools employed for in vitro and in vivo analyses. Thus, development in biosensors and related technologies will play an important 


\section{WILEY-VCH}

part in improving our understanding over the next five years. Furthermore, the long-term effects of drug carriers are yet to be investigated. In particular, little is known regarding their off-target effects on intricate cellular interactions. Developing an understanding of the biological microenvironment more fully will undoubtedly assist toward the development of more efficient next-generation polymeric carriers. Although significant progress has been achieved on the use of $\mathrm{pH}$ and redox potential in polymeric carriers, these technologies can be further improved by employing more appropriate concentration ranges to mirror the biological microenvironment where drug delivery is desired. Additionally, further progress can be made by examining biological materials such as enzymes. The use of enzyme-responsive peptide components affords specific and targeted biological responses, and thus has strong potential for incorporation into 'smart' polymeric carriers. Using tailored biological building blocks will also be an important tool to advance polymeric carriers for improved outcomes in healthcare and diagnostics.

\section{Acknowledgements}

This work was supported by the Australian Research Council Centre of Excellence in Convergent Bio-Nano Science and Technology (Project number CE140100036) and by the Australian Research Council under the Australian Laureate Fellowship FL120100030 (F.C.), Australian Future Fellowship FT120100564 (G.K.S.) and FT110100265 (A.P.R.J.), and Discovery Early Career Researcher Award DE130100488 (Y.Y.) schemes.

\section{References}

[1] G. K. Such, A. P. R. Johnston, K. Liang, F. Caruso, Prog. Polym. Sci. 2012, 37, 985.

[2] A. P. R. Johnston, G. K. Such, S. L. Ng, F. Caruso, Curr. Opin. Colloid Interface Sci. 2011, 16, 171.

[3] Y. Li, G. H. Gao, D. S. Lee, Adv. Healthcare Mater. 2013, 2, 388.

[4] S. Schoffelen, J. C. M. van Hest, Soft Matter 2012, 8, 1736. 


\section{WILEY-VCH}

[5] G. Pasparakis, N. Krasnogor, L. Cronin, B. G. Davis, C. Alexander, Chem. Soc. Rev. 2010, 39, 286.

[6] J.-W. Yoo, D. J. Irvine, D. E. Discher, S. Mitragotri, Nat. Rev. Drug Discovery 2011, 10, 521.

[7] C. F. Greineder, M. D. Howard, R. Carnemolla, D. B. Cines, V. R. Muzykantov, Blood 2013, 122, 1565.

[8] G. Sahay, W. Querbes, C. Alabi, A. Eltoukhy, S. Sarkar, C. Zurenko, E. Karagiannis, K. Love, D. Chen, R. Zoncu, Y. Buganim, A. Schroeder, R. Langer, D. G. Anderson, Nat. Biotechnol. 2013, 31, 653.

[9] L. Rajendran, H. J. Knolker, K. Simons, Nat. Rev. Drug Discovery 2010, 9, 29.

[10] G. Minotti, P. Menna, E. Salvatorelli, G. Cairo, L. Gianni, Pharmacol. Rev. 2004, 56, 185.

[11] J. K. Buolamwini, Curr. Opin. Chem. Biol 1999, 3, 500.

[12] D. B. Zamble, S. J. Lippard, Trends Biochem. Sci. 1995, 20, 435.

[13] S. Marrache, S. Dhar, Proc. Natl. Acad. Sci. U.S.A. 2012, 109, 16288.

[14] Z. Gu, A. Biswas, M. Zhao, Y. Tang, Chem. Soc. Rev. 2011, 40, 3638.

[15] J. A. Hubbell, S. N. Thomas, M. A. Swartz, Nature 2009, 462, 449.

[16] I. Kim, W. Xu, J. C. Reed, Nat. Rev. Drug Discovery 2008, 7, 1013.

[17] E. Fleige, M. A. Quadir, R. Haag, Adv. Drug Delivery Rev. 2012, 64, 866.

[18] H. J. Moon, Y. Ko du, M. H. Park, M. K. Joo, B. Jeong, Chem. Soc. Rev. 2012, 41, 4860.

[19] P. Y. Shao, B. C. Wang, Y. Z. Wang, J. Li, Y. Q. Zhang, J. Nanomater. 2011.

[20] M. J. Levesque, A. C. Groom, Am. J. Physiol. 1976, 231, 1672.

[21] R. van Sluis, Z. M. Bhujwalla, N. Raghunand, P. Ballesteros, J. Alvarez, S. Cerdan, J.P. Galons, R. J. Gillies, Magn. Reson. Med. 1999, 41, 743.

[22] M. C. Brahimi-Horn, J. Pouyssegur, Essays Biochem. 2007, 43, 165.

[23] I. Canton, G. Battaglia, Chem. Soc. Rev. 2012, 41, 2718.

[24] F. Zhao, Y. Zhao, Y. Liu, X. Chang, C. Chen, Y. Zhao, Small 2011, 7, 1322.

[25] T.-G. Iversen, T. Skotland, K. Sandvig, Nano Today 2011, 6, 176.

[26] G. J. Doherty, H. T. McMahon, Annu. Rev. Biochem. 2009, 78, 857.

[27] R. M. Yates, D. G. Russell, Immunity 2005, 23, 409.

[28] T. E. DeCoursey, V. V. Cherny, D. Morgan, B. Z. Katz, M. C. Dinauer, J. Biol. Chem. 2001, 276, 36063.

[29] J.-P. Behr, CHIMIA Int. J. Chem. 1997, 51, 34.

[30] C. E. Ashley, E. C. Carnes, G. K. Phillips, D. Padilla, P. N. Durfee, P. A. Brown, T. N. Hanna, J. Liu, B. Phillips, M. B. Carter, N. J. Carroll, X. Jiang, D. R. Dunphy, C. L. Willman, D. N. Petsev, D. G. Evans, A. N. Parikh, B. Chackerian, W. Wharton, D. S. Peabody, C. J. Brinker, Nat. Mater. 2011, 10, 389.

[31] A. M. Funhoff, C. F. van Nostrum, G. A. Koning, N. M. E. SchuurmansNieuwenbroek, D. J. A. Crommelin, W. E. Hennink, Biomacromolecules 2003, 5, 32.

[32] R. V. Benjaminsen, M. A. Mattebjerg, J. R. Henriksen, S. M. Moghimi, T. L. Andresen, Mol. Ther. 2013, 21, 149.

[33] A. Savina, C. Jancic, S. Hugues, P. Guermonprez, P. Vargas, I. C. Moura, A. M. Lennon-Dumenil, M. C. Seabra, G. Raposo, S. Amigorena, Cell 2006, 126, 205.

[34] Q. Jiang, D. A. Griffin, D. F. Barofsky, J. K. Hurst, Chem. Res. Toxicol. 1997, 10, 1080.

[35] J. Llopis, J. M. McCaffery, A. Miyawaki, M. G. Farquhar, R. Y. Tsien, Proc. Natl. Acad. Sci. U.S.A. 1998, 95, 6803.

[36] A. J. Meyer, T. P. Dick, Antioxid. Redox Signaling 2010, 13, 621.

[37] L. Brülisauer, M. A. Gauthier, J.-C. Leroux, J. Controlled Release 2014, 195, 147.

[38] A. Andersson, A. Isaksson, L. Brattstrom, B. Hultberg, Clin. Chem. 1993, 39, 1590. 


\section{WILEY-VCH}

[39] J. P. Richie, Jr., L. Skowronski, P. Abraham, Y. Leutzinger, Clin. Chem. 1996, 42, 64.

[40] F. Q. Schafer, G. R. Buettner, Free Radical Biol. Med. 2001, 30, 1191.

[41] C. C. Winterbourn, Nat. Chem. Biol. 2008, 4, 278.

[42] C. Lopez-Otin, L. M. Matrisian, Nat. Rev. Cancer 2007, 7, 800.

[43] H. H. Versteeg, J. W. Heemskerk, M. Levi, P. H. Reitsma, Physiol. Rev. 2013, 93, 327.

[44] N. Korin, M. Kanapathipillai, B. D. Matthews, M. Crescente, A. Brill, T. Mammoto, K. Ghosh, S. Jurek, S. A. Bencherif, D. Bhatta, A. U. Coskun, C. L. Feldman, D. D. Wagner, D. E. Ingber, Science 2012, 337, 738.

[45] K. Y. Lin, J. H. Lo, N. Consul, G. A. Kwong, S. N. Bhatia, ACS Nano 2014, 8, 8776.

[46] H. Nagase, J. F. Woessner, Jr., J. Biol. Chem. 1999, 274, 21491.

[47] M. Egeblad, Z. Werb, Nat. Rev. Cancer 2002, 2, 161.

[48] R. J. Tan, Y. Liu, Am. J. Physiol. 2012, 302, F1351.

[49] R. P. Iyer, N. L. Patterson, G. B. Fields, M. L. Lindsey, Am. J. Physiol. 2012, 303, H919.

[50] Q. Cai, Z. Zhao, C. Antalis, L. Yan, G. Del Priore, A. H. Hamed, F. B. Stehman, J. M. Schilder, Y. Xu, FASEB J. 2012, 26, 3306.

[51] C. Shuyan, Y. Lihua, T. J. Cunningham, PLoS One 2012, 7, 1.

[52] M. Murakami, G. Lambeau, Biochimie 2013, 95, 43.

[53] J. N. Mock, L. J. Costyn, S. L. Wilding, R. D. Arnold, B. S. Cummings, Integr. Biol. 2013, 5, 172.

[54] Y. Yan, G. K. Such, A. P. R. Johnston, J. P. Best, F. Caruso, ACS Nano 2012, 6, 3663.

[55] N. D. Rawlings, F. R. Morton, A. J. Barrett, Nucleic Acids Res. 2006, 34, D270.

[56] G. P. Shi, J. A. Villadangos, G. Dranoff, C. Small, L. Gu, K. J. Haley, R. Riese, H. L. Ploegh, H. A. Chapman, Immunity 1999, 10, 197.

[57] M. M. Mohamed, B. F. Sloane, Nat. Rev. Cancer 2006, 6, 764.

[58] J. Qian, C. Winkler, M. Bollen, Curr. Opin. Cell Biol. 2013, 25, 697.

[59] E. Krebs, Biosci. Rep. 1993, 13, 127.

[60] N. K. Tonks, FEBS J. 2013, 280, 346.

[61] M. Hjerrild, S. Gammeltoft, FEBS Lett. 2006, 580, 4764.

[62] M. Radu, G. Semenova, R. Kosoff, J. Chernoff, Nat. Rev. Cancer 2014, 14, 25.

[63] M. Sabbah, S. Emami, G. Redeuilh, S. Julien, G. Prévost, A. Zimber, R. Ouelaa, M. Bracke, O. De Wever, C. Gespach, Drug Resist. Updates 2008, 11, 123.

[64] S. Mizrachy-Schwartz, N. Cohen, S. Klein, N. Kravchenko-Balasha, A. Levitzki, J. Biol. Chem. 2011, 286, 15268.

[65] M. A. Gorin, Q. Pan, Mol. Cancer 2009, 8, 9.

[66] P. M. Brauer, Y. Zheng, L. Wang, A. L. Tyner, Cell Cycle 2010, 9, 4190.

[67] E. A. Dominic, A. Ramezani, S. D. Anker, M. Verma, N. Mehta, M. Rao, Heart (British Cardiac Society) 2014, 100, 611.

[68] H. Akl, T. Vervloessem, S. Kiviluoto, M. Bittremieux, J. B. Parys, H. De Smedt, G. Bultynck, Biochim. Biophys. Acta 2014.

[69] P. J. Randle, P. J. England, R. M. Denton, Biochem. J. 1970, 117, 677.

[70] S. Wen, D. Zhu, P. Huang, Future Med. Chem. 2012, 5, 53.

[71] D. Trachootham, H. Zhang, W. Zhang, L. Feng, M. Du, Y. Zhou, Z. Chen, H. Pelicano, W. Plunkett, W. G. Wierda, M. J. Keating, P. Huang, Blood 2008, 112, 1922.

[72] D. Trachootham, J. Alexandre, H. Peng, Nat. Rev. Drug Discovery 2009, 8, 579.

[73] W. Lu, M. A. Ogasawara, P. Huang, Drug Discovery Today: Dis. Models 2007, 4, 67.

[74] K. Bedard, K. H. Krause, Physiol. Rev. 2007, 87, 245.

[75] J. Kuroda, J. Sadoshima, J. Cardiovasc. Transl. Res. 2010, 3, 314.

[76] J. Breitling, M. Aebi, Cold Spring Harbor Perspect. Biol. 2013, 5, a013359.

[77] I. Brockhausen, S. Narasimhan, H. Schachter, Biochimie 1988, 70, 1521. 


\section{WILEY-VCH}

[78] N. Uozumi, S. Yanagidani, E. Miyoshi, Y. Ihara, T. Sakuma, C. X. Gao, T. Teshima, S. Fujii, T. Shiba, N. Taniguchi, J. Biol. Chem. 1996, 271, 27810.

[79] S. S. Pinho, H. Osorio, M. Nita-Lazar, J. Gomes, C. Lopes, F. Gartner, C. A. Reis, Biochem. Biophys. Res. Commun. 2009, 379, 1091.

[80] S. G. Swygert, C. L. Peterson, Biochim. Biophys. Acta 2014.

[81] S. E. Bojesen, J. Intern. Med. 2013, 274, 399.

[82] J. Pal, J. S. Gold, N. C. Munshi, M. A. Shammas, Transl. Res. 2013, 162, 364.

[83] V. Boccardi, G. Paolisso, Ageing Res. Rev. 2014, 1.

[84] S. F. van Dongen, H. P. de Hoog, R. J. Peters, M. Nallani, R. J. Nolte, J. C. van Hest, Chem. Rev. 2009, 109, 6212.

[85] S. R. MacEwan, A. Chilkoti, J. Controlled Release 2014, 190, 314.

[86] Y. Hu, T. Litwin, A. R. Nagaraja, B. Kwong, J. Katz, N. Watson, D. J. Irvine, Nano Lett. 2007, 7, 3056.

[87] X. F. Su, J. Fricke, D. G. Kavanagh, D. J. Irvine, Mol. Pharm. 2011, 8, 774.

[88] X. Su, N. Yang, D. Wittrup, D. J. Irvine, Biomacromolecules 2013, 14, 1093.

[89] J. M. Morachis, E. A. Mahmoud, J. Sankaranarayanan, A. Almutairi, in J. Drug Delivery, 2012, 1.

[90] M. L. Viger, J. Sankaranarayanan, C. de Gracia Lux, M. Chan, A. Almutairi, J. Am. Chem. Soc. 2013, 135, 7847.

[91] E. M. Bachelder, T. T. Beaudette, K. E. Broaders, J. Dashe, J. M. J. Frechet, J. Am. Chem. Soc. 2008, 130, 10494.

[92] J. A. Cohen, T. T. Beaudette, J. L. Cohen, K. E. Broaders, E. M. Bachelder, J. M. J. Frechet, Adv. Mater. 2010, 22, 3593.

[93] J. Cui, Y. Yan, G. K. Such, K. Liang, C. J. Ochs, A. Postma, F. Caruso, Biomacromolecules 2012, 13, 2225.

[94] X.-Z. Yang, J.-Z. Du, S. Dou, C.-Q. Mao, H.-Y. Long, J. Wang, ACS Nano 2012, 6, 771.

[95] H. Lomas, M. Massignani, K. A. Abdullah, I. Canton, C. Lo Presti, S. MacNeil, J. Du, A. Blanazs, J. Madsen, S. P. Armes, A. L. Lewis, G. Battaglia, Faraday Discuss. 2008, 139, 143.

[96] M. Massignani, C. LoPresti, A. Blanazs, J. Madsen, S. P. Armes, A. L. Lewis, G. Battaglia, Small 2009, 5, 2424.

[97] K. Zhou, Y. Wang, X. Huang, K. Luby-Phelps, B. D. Sumer, J. Gao, Angew. Chem. Int. Ed. 2011, 50, 6109.

[98] J. Y. Ko, S. Park, H. Lee, H. Koo, M. S. Kim, K. Choi, I. C. Kwon, S. Y. Jeong, K. Kim, D. S. Lee, Small 2010, 6, 2539.

[99] Y. G. Wang, K. J. Zhou, G. Huang, C. Hensley, X. N. Huang, X. P. Ma, T. Zhao, B. D. Sumer, R. J. DeBerardinis, J. M. Gao, Nat. Mater. 2014, 13, 204.

[100] H. Yu, Y. Zou, Y. Wang, X. Huang, G. Huang, B. D. Sumer, D. A. Boothman, J. Gao, ACS Nano 2011, 5, 9246.

[101] K. Liang, G. K. Such, A. P. R. Johnston, Z. Zhu, H. Ejima, J. J. Richardson, J. Cui, F. Caruso, Adv. Mater. 2014, 26, 1901.

[102] K. Liang, J. J. Richardson, H. Ejima, G. K. Such, J. Cui, F. Caruso, Adv. Mater. 2014, 26, 2398.

[103] K. Liang, S. T. Gunawan, J. J. Richardson, G. K. Such, J. Cui, F. Caruso, Adv. Healthcare Mat. 2014, 3, 1551.

[104] M. Yan, J. Du, Z. Gu, M. Liang, Y. Hu, W. Zhang, S. Priceman, L. Wu, H. Zhou, Z. Liu, T. Seguara, Y. Tang, L. Yunfeng, Nat. Nanotechnol. 2010, 5, 48.

[105] M. Yan, M. Liang, J. Wen, Y. Liu, Y. Lu, I. S. Chen, J. Am. Chem. Soc. 2012, 134, 13542. 


\section{WILEY-VCH}

[106] K. Liang, G. K. Such, Z. Zhu, Y. Yan, H. Lomas, F. Caruso, Adv. Mater. 2011, 23, H273.

[107] K. Liang, G. K. Such, Z. Zhu, S. J. Dodds, A. P. Johnston, J. Cui, H. Ejima, F. Caruso, ACS Nano 2012, 6, 10186.

[108] J. Dai, S. Lin, D. Cheng, S. Zhou, X. Shuai, Angew. Chem. Int. Ed. 2011, 50, 9404.

[109] E. A. Scott, A. Stano, M. Gillard, A. C. Maio-Liu, M. A. Swartz, J. A. Hubbell, Biomaterials 2012, 33, 6211.

[110] S. Cerritelli, C. P. O’Neil, D. Velluto, A. Fontana, M. Adrian, J. Dubochet, J. A. Hubbell, Langmuir 2009, 25, 11328.

[111] W. F. Dong, A. Kishimura, Y. Anraku, S. Chuanoi, K. Kataoka, J. Am. Chem. Soc. 2009, 131, 3804.

[112] T. Suma, K. Miyata, Y. Anraku, S. Watanabe, R. J. Christie, H. Takemoto, M. Shioyama, N. Gouda, T. Ishii, N. Nishiyama, K. Kataoka, ACS Nano 2012, 6, 6693.

[113] J. Xu, D. H. C. Wong, J. D. Byrne, K. Chen, C. Bowerman, J. M. DeSimone, Angew. Chem. Int. Ed. 2013, 52, 6580.

[114] S. S. Dunn, S. Tian, S. Blake, J. Wang, A. L. Galloway, A. Murphy, P. D. Pohlhaus, J. P. Rolland, M. E. Napier, J. M. DeSimone, J. Am. Chem. Soc. 2012, 134, 7423.

[115] A. N. Zelikin, A. L. Becker, A. P. R. Johnston, K. L. Wark, F. Turatti, F. Caruso, ACS Nano 2007, 1, 63.

[116] A. L. Becker, A. N. Zelikin, A. P. R. Johnston, F. Caruso, Langmuir 2009, 25, 14079.

[117] A. L. Becker, A. P. R. Johnston, F. Caruso, Small 2010, 6, 1836.

[118] K. Kempe, S. L. Ng, S. T. Gunawan, K. F. Noi, F. Caruso, Adv. Funct. Mater. 2014, 24, 6187.

[119] C. R. Kinnane, G. K. Such, G. Antequera-Garcia, Y. Yan, S. J. Dodds, L. M. LizMarzan, F. Caruso, Biomacromolecules 2009, 10, 2839.

[120] S. L. Ng, G. K. Such, A. P. R. Johnston, G. Antequera-Garcia, F. Caruso, Biomaterials 2011, 32, 6277.

[121] M. K. Leung, G. K. Such, A. P. R. Johnston, D. P. Biswas, Z. Zhu, Y. Yan, J. F. Lutz, F. Caruso, Small 2011, 7, 1075.

[122] M. Zhao, A. Biswas, B. Hu, K.-I. Joo, P. Wang, Z. Gu, Y. Tang, Biomaterials 2011, 22, 5223.

[123] A. Sulistio, A. Widjaya, A. Blencowe, X. Zhang, G. Qiao, Chem. Commun. 2011, 47, 1151.

[124] W. Chen, M. Zheng, F. Meng, R. Cheng, C. Deng, J. Feijen, Z. Zhong, Biomacromolecules 2013, 14, 1214.

[125] Z. Zhang, L. Yin, C. Tu, Z. Song, Y. Zhang, Y. Xu, R. Tong, Q. Zhou, J. Ren, J. Cheng, ACS Macro Lett. 2013, 2, 40.

[126] P. Kuppusamy, H. Li, G. Ilangovan, A. J. Cardounel, J. L. Zweier, K. Yamada, M. C. Krishna, J. B. Mitchell, Cancer Res. 2002, 62, 307.

[127] G. Saito, J. A. Swanson, K. D. Lee, Adv. Drug Delivery Rev. 2003, 55, 199.

[128] K. Engin, D. B. Leeper, J. R. Cater, A. J. Thistlethwaite, L. Tupchong, J. D. McFarlane, Int. J. Hyperthermia 1995, 11, 211.

[129] L. E. Gerweck, K. Seetharaman, Cancer Res. 1996, 56, 1194.

[130] J. J. Sperinde, L. G. Griffith, Macromolecules 1997, 30, 5255.

[131] J. J. Sperinde, L. G. Griffith, Macromolecules 2000, 33, 5476.

[132] R. V. Ulijn, J. Mater. Chem. 2006, 16, 2217.

[133] S. Yamashita, J. Yamashita, K. Sakamoto, K. Inada, Y. Nakashima, K. Murata, T. Saishoji, K. Nomura, M. Ogawa, Cancer 1993, 71, 3058.

[134] T. Abe, K. Sakamoto, H. Kamohara, Y. Hirano, N. Kuwahara, M. Ogawa, Int. J. Cancer 1997, 74, 245.

[135] X. X. Zhang, H. S. Eden, X. Chen, J. Controlled Release 2012, 159, 2. 


\section{WILEY-VCH}

[136] S. Gupta, H. Andresen, J. E. Ghadiali, M. M. Stevens, Small 2010, 6, 1509.

[137] S. Gupta, H. Andresen, M. M. Stevens, Chem. Commun. 2011, 47, 2249.

[138] J. E. Ghadiali, S. B. Lowe, M. M. Stevens, Angew. Chem. Int. Ed. 2011, 50, 3417.

[139] C. Seife, Science 1997, 277, 1602.

[140] V. S. Baranov, O. V. Tarasenko, A. N. Baranov, A. V. Kiselev, T. E. Ivashchenko, O. V. Evgrafov, V. M. Mikhailov, G. Dickson, Genetika 1998, 34, 876.

[141] A. Kichler, C. Leborgne, J. Marz, O. Danos, B. Bechinger, Proc. Natl. Acad. Sci. U.S.A. 2003, 100, 1564.

[142] A. Kichler, A. J. Mason, B. Bechinger, Biochim. Biophys. Acta 2006, 1758, 301.

[143] W. Li, F. Nicol, F. C. Szoka, Jr., Adv. Drug Delivery Rev. 2004, 56, 967.

[144] M. Magzoub, A. Pramanik, A. Graslund, Biochemistry 2005, 44, 14890.

[145] P. Midoux, A. Kichler, V. Boutin, J. C. Maurizot, M. Monsigny, Bioconjugate Chem. 1998, 9, 260.

[146] M. C. Morris, L. Chaloin, J. Mery, F. Heitz, G. Divita, Nucleic Acids Res. 1999, 27, 3510.

[147] K. Rittner, A. Benavente, A. Bompard-Sorlet, F. Heitz, G. Divita, R. Brasseur, E. Jacobs, Mol. Ther. 2002, 5, 104.

[148] J. S. Wadia, R. V. Stan, S. F. Dowdy, Nat. Med. 2004, 10, 310.

[149] T. B. Wyman, F. Nicol, O. Zelphati, P. V. Scaria, C. Plank, F. C. Szoka, Jr., Biochemistry 1997, 36, 3008.

[150] S. B. Fonseca, M. P. Pereira, S. O. Kelley, Adv. Drug Delivery Rev. 2009, 61, 953.

[151] E. Koren, V. P. Torchilin, Trends Mol. Med. 2012, 18, 385.

[152] F. Milletti, Drug Discovery Today 2012, 17, 850.

[153] E. S. Olson, T. A. Aguilera, T. Jiang, L. G. Ellies, Q. T. Nguyen, E. H. Wong, L. A. Gross, R. Y. Tsien, Integr. Biol. 2009, 1, 382.

[154] J. Zhong, Y. Chau, Mol. Cancer Ther. 2008, 7, 2933.

[155] I. L. Shih, Y. T. Van, M. H. Shen, Mini-Rev. Med. Chem. 2004, 4, 179.

[156] S. A. Shaffer, C. Baker Lee, A. Kumar, J. W. Singer, Eur. J. Cancer 2002, 38, S129.

[157] R. Duncan, Nat. Rev. Cancer 2006, 6, 688.

[158] R. Duncan, Biochem. Soc. Trans. 2007, 35, 56.

[159] W. Tansey, S. Ke, X. Y. Cao, M. J. Pasuelo, S. Wallace, C. Li, J. Controlled Release 2004, 94, 39.

[160] M. J. Webber, C. J. Newcomb, R. Bitton, S. I. Stupp, Soft Matter 2011, 7, 9665.

[161] Y. S. Cho, Y. G. Park, Y. N. Lee, M.-K. Kim, S. Bates, L. Tan, Y. S. Cho-Chung, Proc. Natl. Acad. Sci. U.S.A. 2000, 97, 835.

[162] M. V. Nesterova, N. Johnson, C. Cheadle, S. E. Bates, S. Mani, C. A. Stratakis, I. Kahn, R. K. Gupta, Y. S. Cho-Chung, Cancer Res. 2006, 66, 8971.

[163] H. Wang, M. Li, W. Lin, W. Wang, Z. Zhang, E. R. Rayburn, J. Lu, D. Chen, X. Yue, F. Shen, F. Jiang, J. He, W. Wei, X. Zeng, R. Zhang, Cancer Epidemiol., Biomarkers Prev. 2007, 16, 789.

[164] J. W. Valle, J. Lawrance, J. Brewer, A. Clayton, P. Corrie, V. Alakhov, M. Ranson, J. Clin. Oncol. 2004, 22, 362S.

[165] T. Minko, E. V. Batrakova, S. Li, Y. Li, R. I. Pakunlu, V. Y. Alakhov, A. V. Kabanov, J. Controlled Release 2005, 105, 269.

[166] V. K. Garripelli, J. K. Kim, S. Son, W. J. Kim, M. A. Repka, S. Jo, Acta Biomater. 2011, 7, 1984.

[167] D. Bacinello, E. Garanger, D. Taton, K. C. Tam, S. Lecommandoux, Biomacromolecules 2014, 15, 1882.

[168] P. F. Caponi, X. P. Qiu, F. Vilela, F. M. Winnik, R. V. Ulijn, Polym. Chem. 2011, 2, 306. 


\section{WILEY-VCH}

[169] K. Bosslet, R. Straub, M. Blumrich, J. Czech, M. Gerken, B. Sperker, H. K. Kroemer, J. P. Gesson, M. Koch, C. Monneret, Cancer Res. 1998, 58, 1195.

[170] F. Kratz, A. Warnecke, B. Schmid, D. E. Chung, M. Gitzel, Curr. Med. Chem. 2006, 13, 477.

[171] P. D. Senter, FASEB J. 1990, 4, 188.

[172] L. F. Tietze, H. J. Schuster, K. Schmuck, I. Schuberth, F. Alves, Bioorg. Med. Chem. 2008, 16, 6312.

[173] G. M. Dubowchik, R. A. Firestone, Bioorg. Med. Chem. Lett. 1998, 8, 3341.

[174] V. Lemieux, P. H. Adams, J. C. van Hest, Chem. Commun. 2010, 46, 3071.

[175] R. Madec-Lougerstay, J.-C. Florent, C. Monneret, J. Chem. Soc., Perkin Trans. 1 1999, 1369.

[176] J. P. Irigoyen, P. Munoz-Canoves, L. Montero, M. Koziczak, Y. Nagamine, Cell. Mol. Life Sci. 1999, 56, 104.

[177] A. D. Wong, M. A. DeWit, E. R. Gillies, Adv. Drug Delivery Rev. 2012, 64, 1031.

[178] C. E. Brubaker, P. B. Messersmith, Biomacromolecules 2011, 12, 4326.

[179] M. P. Lutolf, G. P. Raeber, A. H. Zisch, N. Tirelli, J. A. Hubbell, Adv. Mater. 2003, 15, 888.

[180] D. Gabriel, M. A. Campo, R. Gurny, N. Lange, Bioconjugate Chem. 2007, 18, 1070.

[181] P. R. Kumaresan, A. Natarajan, A. Song, X. Wang, R. Liu, G. DeNardo, S. DeNardo, K. S. Lam, Bioconjugate Chem. 2007, 18, 175.

[182] A. Trouet, M. Masquelier, R. Baurain, D. Deprez-De Campeneere, Proc. Natl. Acad. Sci. U.S.A. 1982, 79, 626.

[183] Y. Shiose, H. Kuga, H. Ohki, M. Ikeda, F. Yamashita, M. Hashida, Bioconjugate Chem. 2009, 20, 60.

[184] L. W. Seymour, D. R. Ferry, D. J. Kerr, D. Rea, M. Whitlock, R. Poyner, C. Boivin, S. Hesslewood, C. Twelves, R. Blackie, A. Schatzlein, D. Jodrell, D. Bissett, H. Calvert, M. Lind, A. Robbins, S. Burtles, R. Duncan, J. Cassidy, Int. J. Oncol. 2009, 34, 1629.

[185] P. A. Vasey, S. B. Kaye, R. Morrison, C. Twelves, P. Wilson, R. Duncan, A. H. Thomson, L. S. Murray, T. E. Hilditch, T. Murray, S. Burtles, D. Fraier, E. Frigerio, J. Cassidy, Clin. Cancer Res. 1999, 5, 83.

[186] C. S. Gondi, J. S. Rao, Expert Opin. Ther. Targets 2013, 17, 281.

[187] I. Podgorski, B. F. Sloane, Biochem. Soc. Symp. 2003, 70, 263.

[188] A. M. Szpaderska, A. Frankfater, Cancer Res. 2001, 61, 3493.

[189] V. Turk, B. Turk, D. Turk, EMBO J. 2001, 20, 4629.

[190] C. N. Yang, Y. J. Shiao, F. S. Shie, B. S. Guo, P. H. Chen, C. Y. Cho, Y. J. Chen, F. L. Huang, H. J. Tsay, Neurobiol. Dis. 2011, 42, 221.

[191] R. Duncan, H. C. Cable, J. B. Lloyd, P. Rejmanová, J. Kopeček, Biosci. Rep. 1982, 2, 1041.

[192] R. Duncan, M. K. Pratten, H. C. Cable, H. Ringsdorf, J. B. Lloyd, Biochem. J. 1981, 196, 49.

[193] L. W. Seymour, R. Duncan, J. Strohalm, J. Kopecek, J. Biomed. Mater. Res. 1987, 21, 1341.

[194] L. W. Seymour, Y. Miyamoto, H. Maeda, M. Brereton, J. Strohalm, K. Ulbrich, R. Duncan, Eur. J. Cancer 1995, 31A, 766.

[195] R. Duncan, L. W. Seymour, K. B. O'Hare, P. A. Flanagan, S. Wedge, I. C. Hume, K. Ulbrich, J. Strohalm, V. Subr, F. Spreafico, M. Grandi, M. Ripamonti, M. Farao, A. Suarato, J. Controlled Release 1992, 19, 331.

[196] B. Apostolovic, S. P. Deacon, R. Duncan, H. A. Klok, Biomacromolecules 2010, 11, 1187.

[197] Y. G. Yu, D. S. King, Y. K. Shin, Science 1994, 266, 274. 


\section{WILEY-VCH}

[198] T. Etrych, L. Kovar, J. Strohalm, P. Chytil, B. Rihova, K. Ulbrich, J. Controlled Release 2011, 154, 241.

[199] T. Etrych, J. Strohalm, P. Chytil, P. Cernoch, L. Starovoytova, M. Pechar, K. Ulbrich, Eur. J. Pharm. Sci. 2011, 42, 527.

[200] R. Shankar, A. Samykutty, C. Riggin, S. Kannan, U. Wenzel, R. Kolhatkar, Mol. Pharm. 2013, 10, 3776.

[201] J. S. Lee, T. Groothuis, C. Cusan, D. Mink, J. Feijen, Biomaterials 2011, 32, 9144.

[202] M. Shamis, H. N. Lode, D. Shabat, J. Am. Chem. Soc. 2004, 126, 1726.

[203] K. Haba, M. Popkov, M. Shamis, R. A. Lerner, C. F. Barbas, 3rd, D. Shabat, Angew. Chem. Int. Ed. 2005, 44, 716.

[204] R. de la Rica, D. Aili, M. M. Stevens, Adv. Drug Delivery Rev. 2012, 64, 967.

[205] C. C. Pak, S. Ali, A. S. Janoff, P. Meers, Biochim. Biophys. Acta 1998, 1372, 13.

[206] J. I. Yamashita, M. Ogawa, S. Ikei, H. Omachi, S. I. Yamashita, T. Saishoji, K. Nomura, H. Sato, Br. J. Cancer 1994, 69, 72.

[207] B. Starcher, P. O'Neal, R. D. Granstein, S. Beissert, J. Invest. Dermatol. 1996, 107, 159.

[208] T. Terada, M. Iwai, S. Kawakami, F. Yamashita, M. Hashida, J. Controlled Release 2006, 111, 333.

[209] S. T. Gunawan, K. Liang, G. K. Such, A. P. Johnston, M. K. Leung, J. Cui, F. Caruso, Small 2014, 10, 4080.

[210] P. D. Thornton, R. J. Mart, S. J. Webb, R. V. Ulijn, Soft Matter 2008, 4, 821.

[211] L. C. Glangchai, M. Caldorera-Moore, L. Shi, K. Roy, J. Controlled Release 2008, 125, 263.

Received: ((will be filled in by the editorial staff))

Revised: ((will be filled in by the editorial staff))

Published online: ((will be filled in by the editorial staff)) 


\section{WILEY-VCH}

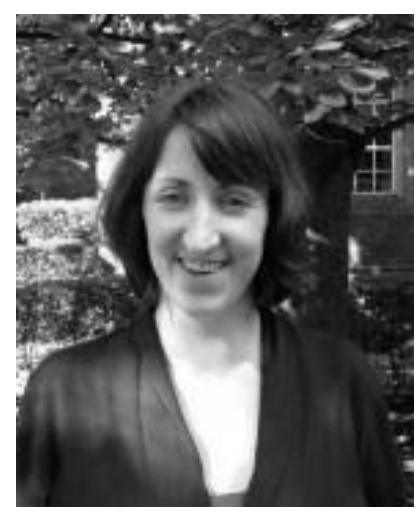

Georgina Such is currently an ARC Future Fellow in the School of Chemistry at The University of Melbourne. She completed her PhD in 2006 from the University of New South Wales and then worked until 2012 in the Nanostructured Interfaces and Materials Science (NIMS) group headed by Prof. Frank Caruso. Her research interests include intelligent polymer design, nanoparticle self-assembly, and therapeutic delivery.

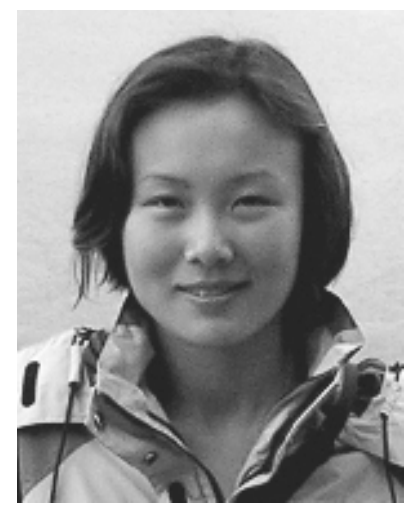

Yan Yan is an ARC DECRA research fellow in the group led by Prof. Frank Caruso at The University of Melbourne. She received her PhD in Biochemistry and Molecular Biology from Peking University in 2008. Her current research focuses on understanding cellular dynamics of nano-engineered materials. 


\section{WILEY-VCH}

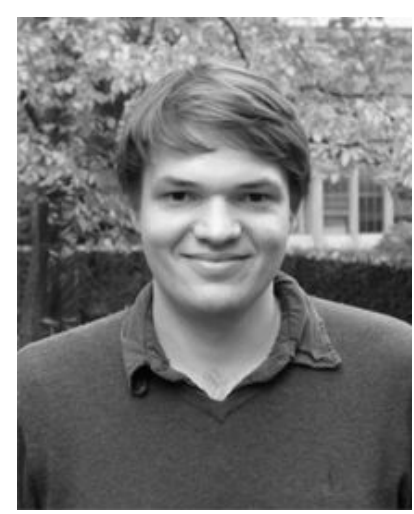

Angus Johnston is the Head of the NanoMaterials for Biology Group at the Monash Institute of Pharmaceutical Sciences. He received his $\mathrm{PhD}$ from the Department of Chemistry at the University of Queensland in 2006 and worked as a research fellow with Prof. Frank Caruso at The University of Melbourne until 2011. His research focuses on understanding the interactions of nanomaterials with cells, in particular developing molecular sensors to understand the internalization, trafficking, and release of drugs in cells.

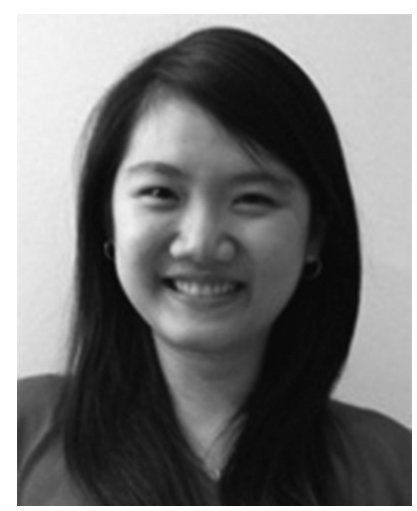

Sylvia Gunawan received her Bachelor of Engineering with Honors (Chemical and Biomolecular) in 2011 from The University of Melbourne, Australia, and started her PhD in 2012 under the supervision of Prof. Frank Caruso and Dr. Georgina Such. Her research interests focus on the design of bio-inspired, intelligent polymeric carriers for therapeutic applications. 


\section{WILEY-VCH}

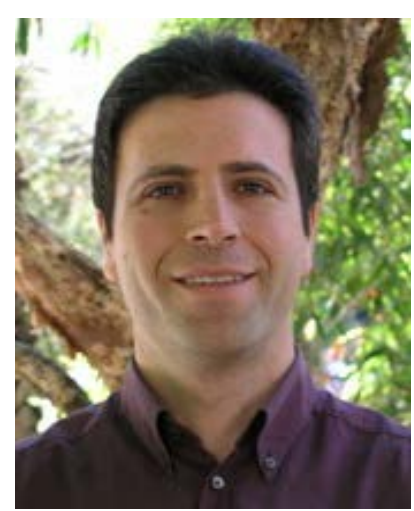

Frank Caruso is a professor and Australian Research Council Australian Laureate Fellow at The University of Melbourne. He received his PhD degree in 1994 from The University of Melbourne. He is listed as one of Thomson Reuters' Highly Cited Researchers and is also included in Thomson Reuters' 2014 World's Most Influential Scientific Minds. His research interests focus on developing advanced nano- and biomaterials for biotechnology and medicine. 


\section{WILEY-VCH}

Improvements in the design of responsive therapeutic carriers for biomedical applications rely on a greater understanding of the biological microenvironments and how such environments can be harnessed to induce carrier responses. This review provides an overview for materials scientists on the relevant biological microenvironments within cells, focusing on $\mathrm{pH}$, redox potential, and enzyme variations - conditions that can aid in the design of intelligent carrier systems. The review also covers recent literature on the design of smart polymeric carriers and future possibilities in advancing such carriers in the biomedical field.

Keywords: polymer carriers, drug delivery, $\mathrm{pH}$, redox, enzyme.

Georgina K. Such, Yan Yan, Angus P. R. Johnston, Sylvia T. Gunawan, and Frank Caruso*

Interfacing Materials Science and Biology for Drug Carrier Design

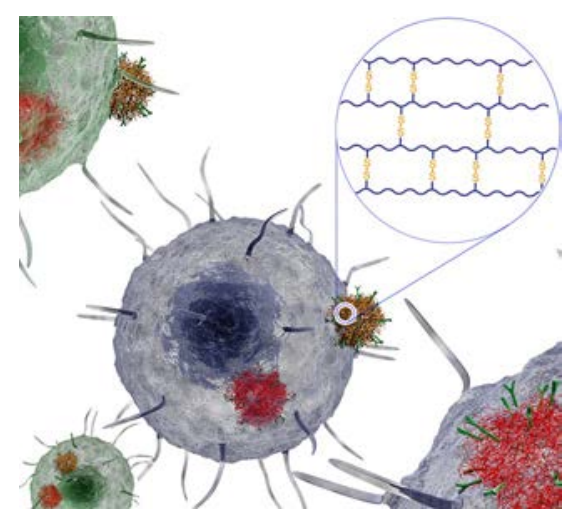




\section{University Library}

\section{- M M N E R VA A gateway to Melbourne's research publications}

Minerva Access is the Institutional Repository of The University of Melbourne

Author/s:

Such, GK;Yan, Y;Johnston, APR;Gunawan, ST;Caruso, F

Title:

Interfacing Materials Science and Biology for Drug Carrier Design

Date:

2015-04-08

Citation:

Such, G. K., Yan, Y., Johnston, A. P. R., Gunawan, S. T. \& Caruso, F. (2015). Interfacing Materials Science and Biology for Drug Carrier Design. ADVANCED MATERIALS, 27 (14), pp.2278-2297. https://doi.org/10.1002/adma.201405084.

Persistent Link:

http://hdl.handle.net/11343/90872 